\title{
PLACENTAL MORPHOLOGY AND THE PREDICTION OF UNDERLYING CRADIOVASCULAR RISK FACTORS
}

by

Aida Zaza

A thesis submitted to the Department of Biomedical and Molecular Sciences

In conformity with the requirements for

the degree of Master of Science

\author{
Queen's University \\ Kingston, Ontario, Canada
}

(September, 2020)

Copyright @Aida Zaza, 2020 


\begin{abstract}
Pre-eclampsia (PE) is associated with an increased risk of future cardiovascular disease (CVD). It is characterized by new onset hypertension and proteinuria, sometimes progressing into a multiorgan clinical manifestation. Maladaptive placentation or malperfusion, as well as predisposing cardiovascular or metabolic risk for endothelial dysfunction, contribute to the systemic inflammatory response that establishes the origins of the disease. The purpose of this study was to investigate the relationship between placental morphology and cardiovascular risk (CVR) when assessed at six months postpartum in women who experienced PE. Multivariable logistic regression was used to examine the relationship between placental morphology measures and calculated maternal lifetime risk of CVD at six months postpartum, with $\mathrm{P}<0.05$ used to define significance. 186/216 women with $\mathrm{PE}$ who attended the Maternal Health Clinic met inclusion criteria. No significant differences were observed for placental morphometric measurements between women who screened as having a high vs. low lifetime risk profile for CVD at six months postpartum. However, using multivariable modelling that controlled for maternal age, pre-pregnancy BMI, gestational age at delivery, and severity of PE, a low placenta to birth weight ratio $(<15 \%)$ was associated with an increased odds of high lifetime CVD risk $(\mathrm{p}<0.009)$. The findings of the current study identify clinical measurements that can be collected at the time of delivery which may help identify specific women who may benefit most from postpartum CVR screening and intervention. It was found that low placental to birthweight ratios, indicative of higher placental efficiency, were associated with an increased odds of high lifetime CVD risk in the mother when screened postpartum. Why underlying maternal CVR factors may lead to increases in placental efficiency are currently unclear, but certainly warrant further investigation and will be important to do a prospective validation study.
\end{abstract}




\section{Co-Authorship}

Aida Zaza, Dr. Shannon Bainbridge, and Dr. Graeme N Smith created the experimental design. Aida Zaza completed all experimental work, with assistance from Nichole Peterson. Jessica Pudwell participated in statistical analysis. All writing was completed by Aida Zaza. Manuscript submitted to Placenta on August $4^{\text {th }}, 2020$. 


\section{Acknowledgements}

I am very grateful for my friends, family, and mentors who have provided endless support throughout my graduate degree. I would like to thank my supervisor, Dr. Graeme Smith, for taking me on as his graduate student and believing in me from the beginning. His passion, optimism, and incredible work ethic will continue to inspire me. I would like to thank Dr. Shannon Bainbridge and Dr. Kristin Connor for their guidance and sharing their expertise with me. I am fortunate to have had the opportunity to collaborate with such amazing leaders in the field of Reproduction and Developmental Sciences and learned about the different implications that my research has on both fetal and maternal health outcomes. I would also like to thank the members of Dr. Smith's lab - Jessica Pudwell, Michelle Roddy, Kira King, Nicki Peterson, and Heather Ramshaw. I could not have done it without Jessica's incredible contribution to the data analysis, Michelle and Kira's dedicated assistance in recruitment, patient follow-up, and data collection, and Nicki and Heather's administrative and technical assistance. Thank you to my colleagues, Logan Barr and Megan Dickson, for creating a positive and encouraging environment where we shared insightful feedback, as well as endless laughs. Over the past two years, I have been introduced to some unforgettable professors at Queen's through my graduate courses, conferences and scientific meetings, and my Research Advisory Committee: Dr. Chandra Tayade, Dr. Charles Graham, Dr. David Natale, and Dr. Amer Johri. I cannot thank you enough for your mentorship. I appreciate that you always made time for any questions I had and your willingness to provide expert advice regarding my thesis and professional development. In addition, the administrative staff of the Faculty of Health Sciences and DBMS have been indispensable in the organization of my graduate degree. Furthermore, The Franklin Bracken Fellowship, allowed me to completely dedicate my time and effort to my thesis project, while encouraging me to delve into volunteer opportunities and extracurricular activities on campus that enriched my University experience. Lastly, I would not be where I am today without the support from my parents, my siblings, and my friends. Their consistent encouragement was immensely uplifting during the most challenging times and will continue to motivate me throughout my career in Science. 


\section{Table of Contents}

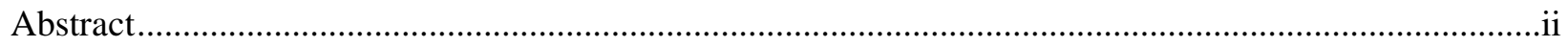

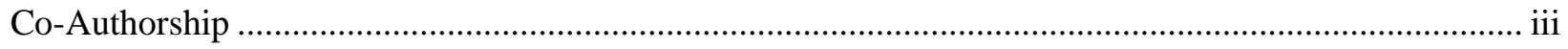

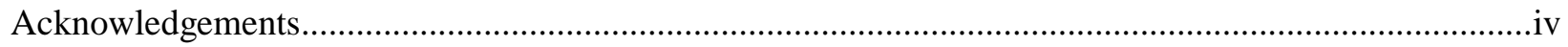

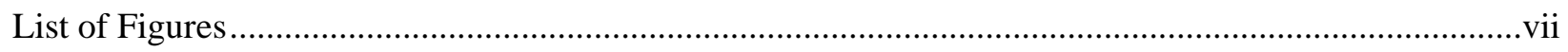

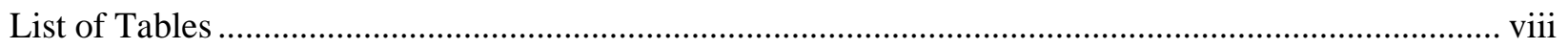

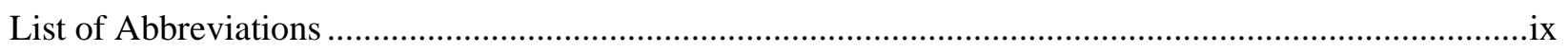

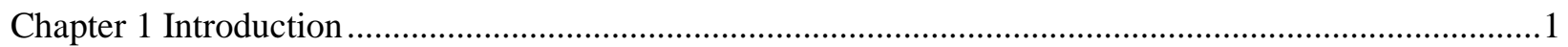

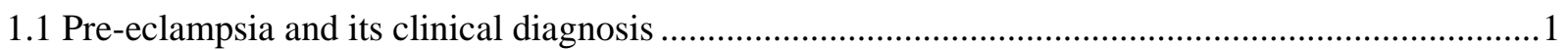

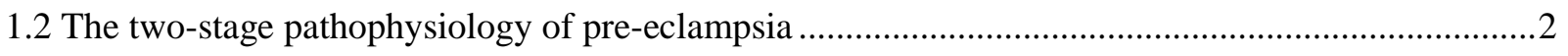

1.2.1 Spiral artery remodeling in a healthy pregnancy ..................................................................

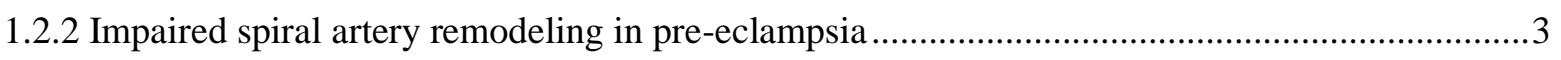

1.3 Markers of vascular and endothelial dysfunction in pre-eclampsia ..............................................5

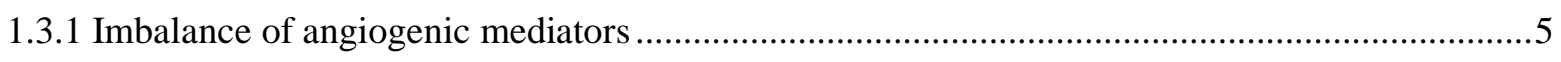

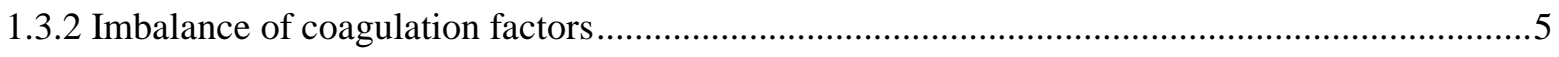

1.4 Maternal endothelial dysfunction and pre-eclampsia ............................................................ 6

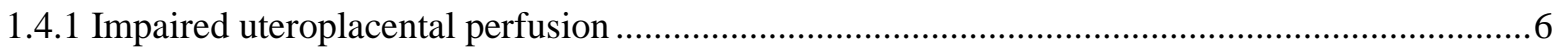

1.4.2 Endothelial function in preeclamptic and normotensive pregnancies .....................................6

1.4.3 Endothelial dysfunction and the development of cardiovascular disease ..................................

1.5 Pre-eclampsia and future cardiovascular disease risk.....................................................................

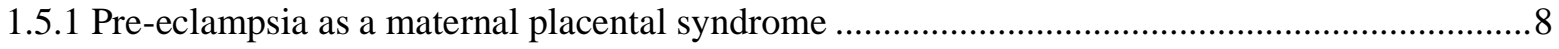

1.5.2 Risk factors for cardiovascular disease in women................................................................

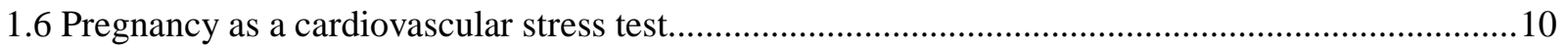

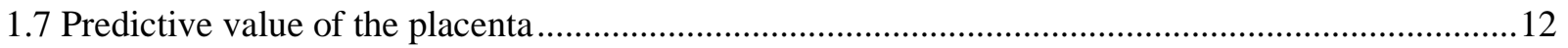

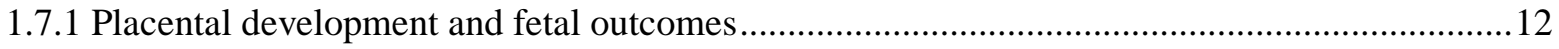

1.7.2 Placental morphometric measurements associated with elevated cardiovascular disease risk ..12

1.8 Molecular and histopathology profiling and subclasses of pre-eclampsia .....................................15

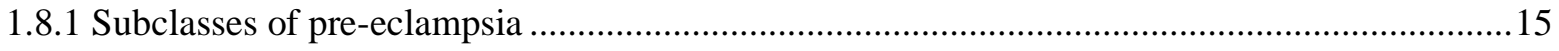

1.8.2 Discriminatory potential of genetic biomarkers between placental clusters .............................16

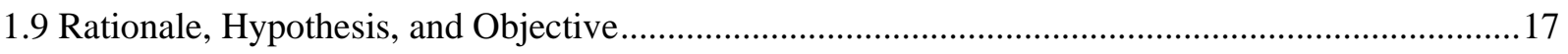

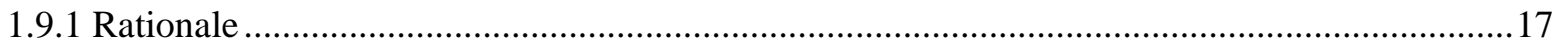

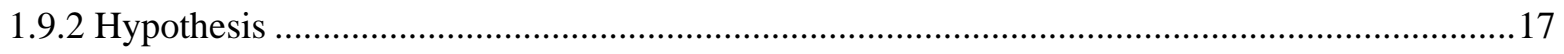

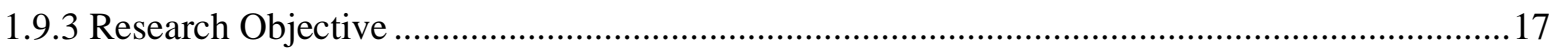




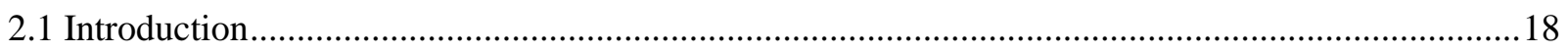

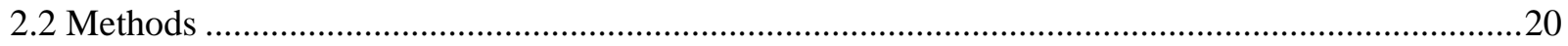

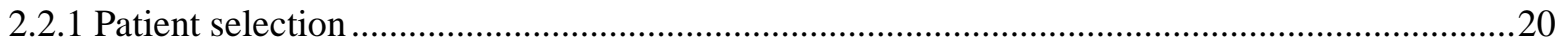

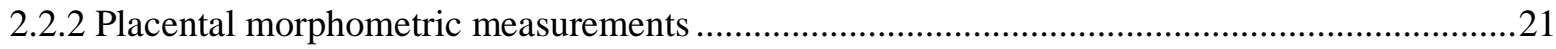

2.2.3 Lifetime cardiovascular disease risk estimation .............................................................21

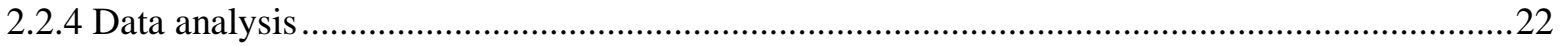

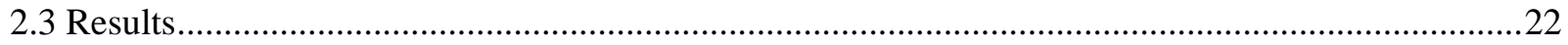

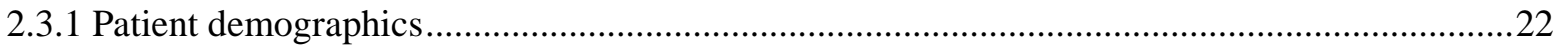

2.3.2 Placental morphology measurements and postpartum lifetime cardiovascular disease risk

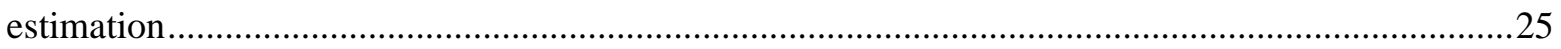

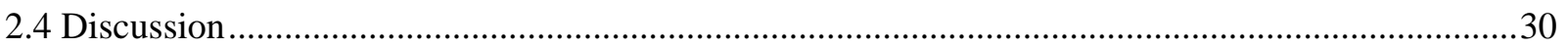

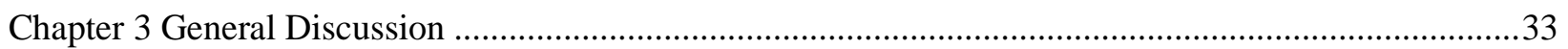

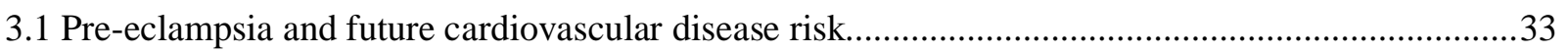

3.1.1 The predictive value of placenta weight to birth weight ratio and the risk of lifetime

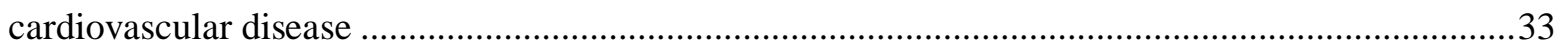

3.1.2 The predictive value of placental weight to birth weight ratio and the risk of metabolic

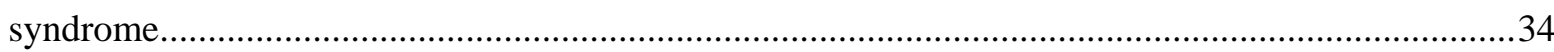

3.1.3 The predictive value of placental length and width and the risk of lifetime cardiovascular

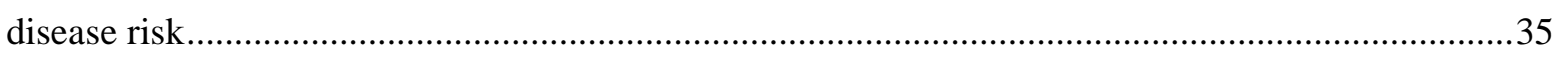

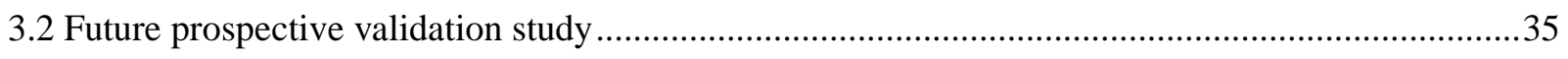

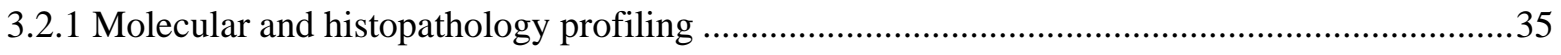

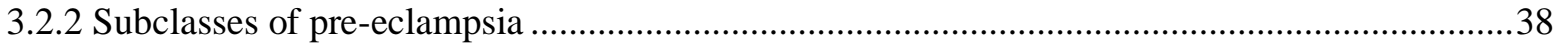

3.2.3 Discriminatory potential of genetic biomarkers between placental clusters ............................39

3.2.4 Subclasses of pre-eclampsia linked to increased risk of cardiovascular disease .......................40

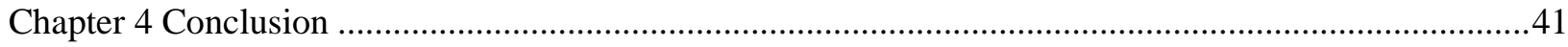

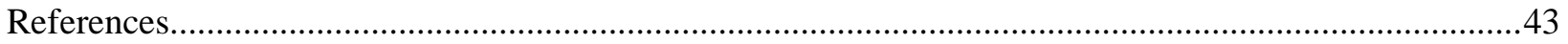

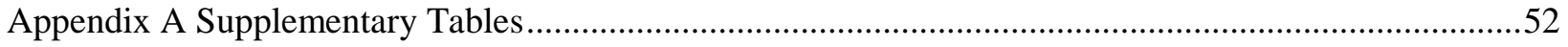




\section{List of Figures}

Figure 1: Two-stage model of the pathophysiology of pre-eclampsia .....................................................

Figure 2: Vascular dysfunction in a normotensive pregnancy and a preeclamptic pregnancy....................11

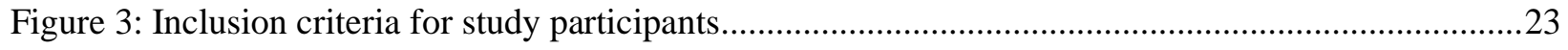

Figure 4: The pathophysiology of pre-eclampsia and the risk of future cardiovascular disease................42 


\section{List of Tables}

Table 1: Maternal clinical characteristics and their lifetime cardiovascular disease risk profiles calculated

at 6 months postpartum

Table 2: Placental morphometric measurements and fetal birth weight collected at the time of delivery..26

Table 3: Placental measurements according to lifetime cardiovascular disease risk profiles calculated at 6

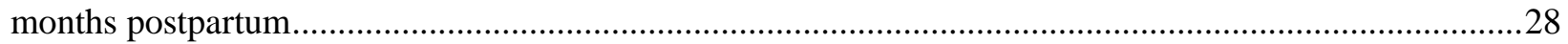

Table 4: Logistic regression models for high lifetime cardiovascular disease risk ..................................29

Table 5: Genetic biomarkers with the greatest discriminatory potential by qPCR. ................................36

Table 6: Histological differences between 19 Cluster 2 and 5 Cluster 3 PE-IUGR samples......................37

Table 7: Maternal clinical characteristics and their lifetime cardiovascular disease risk profiles and metabolic syndrome risk profiles calculated at 6 months postpartum...................................................52

Table 8: Placental measurements according to lifetime cardiovascular disease risk profiles and metabolic

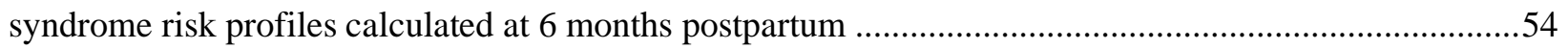

Table 9: Logistic regression models for risk of metabolic syndrome .....................................................56 


\section{List of Abbreviations}

\begin{tabular}{|c|c|}
\hline BMI & Body Mass Index \\
\hline $\mathrm{CI}$ & Confidence Interval \\
\hline CVD & Cardiovascular Disease \\
\hline CVR & Cardiovascular Risk \\
\hline CXCL10 & $\mathrm{C}-\mathrm{X}-\mathrm{C}$ motif chemokine ligand 10 \\
\hline ENG & Endoglin \\
\hline EVT & Extravillous Trophoblasts \\
\hline FLT & Fms-like tyrosine kinase \\
\hline FSLT3 & Follistatin-like 3 \\
\hline GSEA & Gene-Set Enrichment Analysis \\
\hline HELLP & Hemolysis, Elevated Liver enzymes, and Low Platelet count \\
\hline HLA & Human Leucocyte Antigen \\
\hline ICAM-1 & Intercellular Adhesion Molecule-1 \\
\hline IQR & Interquartile Range \\
\hline IUGR & Intrauterine Growth Restriction \\
\hline KHSC & Kingston Health Sciences Centre \\
\hline LHIN & Local Health Integration Network \\
\hline LIMCH1 & LIM and calponin homology domains 1 \\
\hline MHC & Maternal Health Clinic \\
\hline MPS & Maternal Placental Syndromes \\
\hline mRNA & messenger Ribonucleic Acid \\
\hline OR & Odds Ratio \\
\hline PCAM-1 & Platelet Endothelial Cell Adhesion Moleculae-1 \\
\hline PE & Pre-eclampsia \\
\hline
\end{tabular}




$\begin{array}{ll}\text { PIGF } & \text { Placental Growth Factor } \\ \text { PW:BW } & \text { Placenta Weight to Birth Weight } \\ \text { qPCR } & \text { quantitative Polymerase Chain Reaction } \\ \text { SD } & \text { Standard Deviation } \\ \text { sENG } & \text { Soluble Endoglin } \\ \text { sFLT-1 } & \text { Soluble fms-like tyrosine kinase-1 } \\ \text { TAP1 } & \text { Transporter 1, ATP-binding cassette, subfamily B } \\ \text { VCAM-1 } & \text { Vascular Adhesion Molecule-1 } \\ \text { VEGF } & \text { Vascular Endothelial Growth Factor }\end{array}$




\section{Chapter 1}

\section{Introduction}

\subsection{Pre-eclampsia and its clinical diagnosis}

Pre-eclampsia (PE) is a pregnancy complication that affects approximately $4 \%$ of all pregnancies $[1,2]$ and is a major cause of maternal, fetal, and neonatal morbidity and mortality worldwide [3]. The clinical manifestations of PE are characterized by new onset hypertension with systolic blood pressure of $>140 \mathrm{mmHg}$ or diastolic blood pressure of $>90 \mathrm{mmHg}$, along with proteinuria $(\geq 0.3 \mathrm{~g} / 24 \mathrm{~h})$ after 20 weeks of gestation [4]. If proteinuria is not present, other signs or symptoms reflective of other end-organ dysfunction are thrombocytopenia, liver dysfunction, renal insufficiency, pulmonary edema, and cerebral or visual disturbances [3]. Due to its multifactorial nature, the etiology of pre-eclampsia is not fully understood, but it is known to be secondary to impaired placental function or malperfusion. Pre-eclampsia can progress to its more severe form, eclampsia, which is a life-threatening condition that can lead to organ damage or stroke. [3]. Pre-eclampsia may also lead to other severe conditions such as HELLP (hemolysis, elevated liver enzymes, and low platelet count) syndrome, pulmonary edema, renal failure, disseminated intravascular coagulation, and placental abruption [5]. Furthermore, the pathological condition can have detrimental effects on the fetus, including increased risk of fetal death, intrauterine growth restriction, and neurodevelopmental consequences [6]. Despite the presence of advanced medical interventions, delivery remains the only curative treatment, yet it does not absolve the fetus or the mother from long-term health risks. 


\subsection{The two-stage pathophysiology of pre-eclampsia}

\subsubsection{Spiral artery remodeling in a healthy pregnancy}

Although the clinical presentation of PE does not occur until later in gestation, the development of the disorder commences early in pregnancy during placental development. One of the proposed mechanisms of PE involves abnormal placental development as a result of impaired spiral artery remodeling and defective trophoblast invasion [3]. Decidualization is a dynamic pathway whereby the endometrial stromal cells transform from an undifferentiated phenotype to the decidual phenotype in a non-conception cycle [7]. It occurs in species in which placentation involves breaching the maternal epithelium and trophoblast invasion of maternal tissues, as seen in humans [7]. The differentiation of endometrial stromal cells into specialist decidual cells is initiated in each menstrual cycle, regardless of the presence of absence of a conceptus [7]. During the implantation of an embryo, the decidualization process undergoes extensive tissue remodeling by trophoblast invasion to accommodate the growth of the fetus throughout the gestational period. During early pregnancy, trophoblast cells differentiate into two cell types: (1) the inner cytotrophoblasts, and (2) the outer multinucleated syncytiotrophoblast composed of fused cytotrophoblasts which actively migrate into the decidua [8]. During the second week of gestation, cytotrophoblasts begin to invade through the syncytiotrophoblast layer and form projections called chorionic villi. These villi become in direct contact with maternal blood flow to allow for exchange between maternal and fetal circulations. Transitioning into the second trimester of pregnancy, a highly invasive type of cytotrophoblast arise from the anchoring villi, termed extravillous trophoblasts (EVT), that are involved in the vascular remodeling of the maternal arteries that supply the placenta. In a healthy pregnancy, EVTs invade the spiral arteries in the decidua and myometrium, while simultaneously replacing the smooth muscle and endothelial cells from the vessel wall. The spiral arteries progressively lose their vascular smooth muscle and elastic lamina, while being invaded by EVTs that deposit nonactive fibrinoid and replace vascular endothelial cells [8], followed by the deterioration of the medial elastic, muscular, and neural tissue [3]. By the end of the second trimester of pregnancy, the uterine spiral 
arteries are lined exclusively by cytotrophoblasts, completely replacing the endothelial cells in the endometrial or superficial myometrial regions [9]. This remodeling of the uterine spiral arteries results in dilated, low resistance arteriolar system that is insensitive to circulating vasoactive factors so that it is possible to transport the expanded blood volume necessary to optimize exchange at the maternal fetal interface [10]. According to Zhang et al., the vascular changes that occur in response to the breaching of the epithelium and trophoblast invasion include increased permeability, angiogenesis, and structural remodeling of most spiral arteries [9]. This slows maternal blood flow, minimizes turbulence, and improves the exchange time with the fetal circulation [9].

\subsubsection{Impaired spiral artery remodeling in pre-eclampsia}

In contrast, a preeclamptic pregnancy involves an impaired decidualization process of the myometrial spiral arteries and predisposes the women to shallow intravascular trophoblast invasion (Figure 1). The invasion of the uterine spiral arteries is limited to the proximal decidua, with $30 \%$ to $50 \%$ of the spiral arteries of the placental bed not undergoing endovascular trophoblast remodeling [11]. Myometrial segments of these arteries remain anatomically intact and undilated, yet the mean external diameters of the uterine spiral arteries in preeclamptic women are less than one half of the diameters of similar vessels of uncomplicated pregnancies. In normal pregnancies, $96 \%$ of the junctional zone spiral arteries are remodelled, meanwhile only $10 \%$ are remodelled in PE patients [12]. Since the arterial modifications only occur following the trophoblast invasion, the impaired spiral artery remodeling indicated impaired trophoblast function [13]. According to Cotechini et al., they used immunohistochemistry for cytokeratin to identify trophoblasts and alpha-actin to identify smooth muscle, which showed that the mean cross-sectional area of spiral arteries from lipopolysaccharide-induced fetal growth restriction was significantly smaller than the vessels from normal fetal growth control rats [14]. They further explain that an increase in macrophages around the spiral arteries was associated with impaired trophoblast invasion as it inhibits the invasion by secreting tumour necrosis factor [14]. These 
results indicate the role of inflammation in inhibiting spiral artery remodeling, while highlighting that uteroplacental perfusion is necessary to support fetal growth and development.

The failure of vascular remodeling prevents an adequate response to increased fetal demands for blood flow during gestation. This transitions into the second pathophysiological stage of PE in which a maladaptive placental environment is established (Figure 1). The consequence is hypoperfusion of the placenta, hypoxemia, ischemia sequence that causes a release of cytokines such as soluble fms-like tyrosine kinase-1 (sFLT-1) and vascular endothelial growth factor (VEGF) that induce a systemic response, characterized by endothelial dysfunction, widespread inflammation, and the clinical manifestations of PE [3].
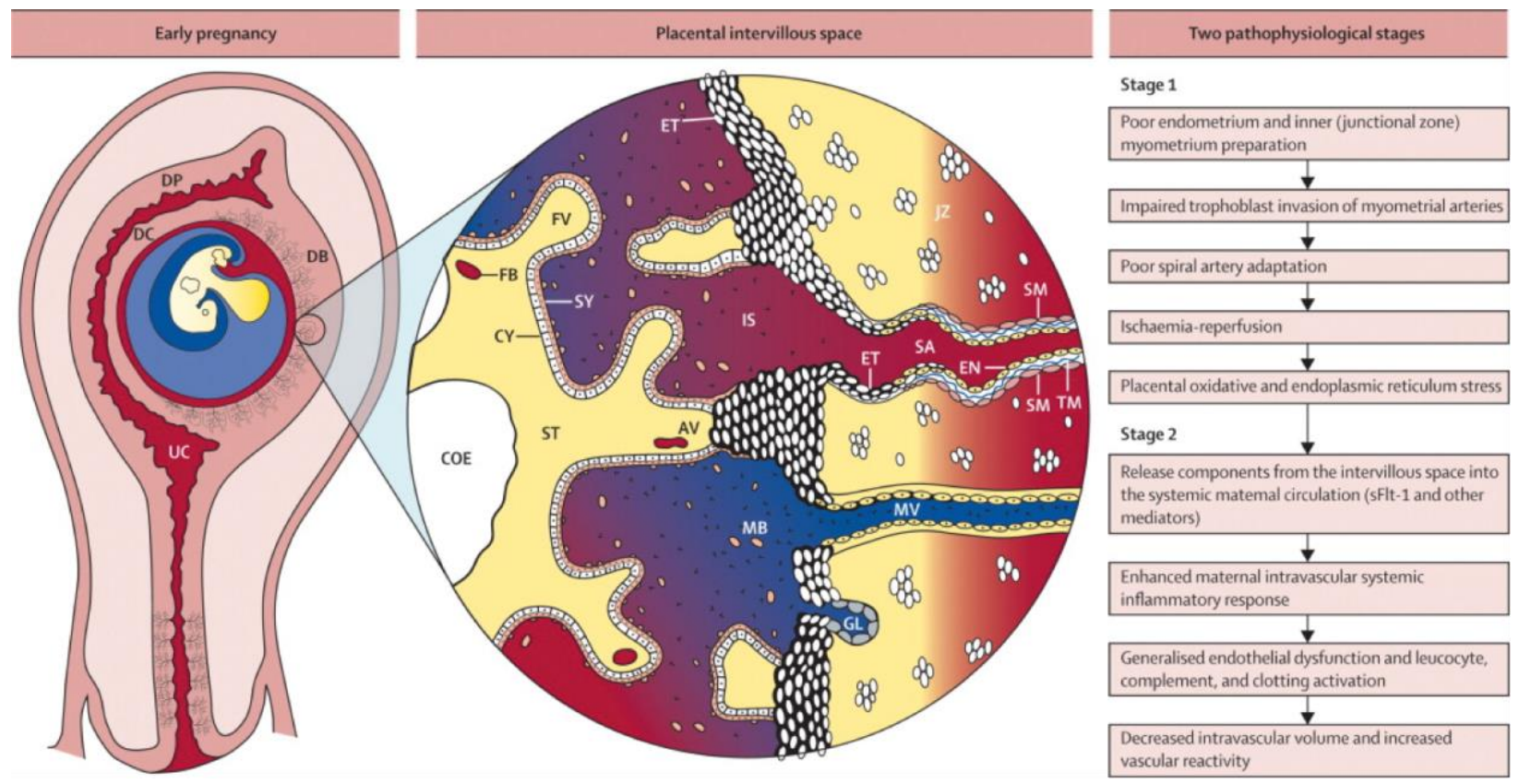

Figure 1: Two-stage model of the pathophysiology of pre-eclampsia. In the first stage, impairment in trophoblast invasion of the myometrial spiral arteries creates a hypoxic utero-placental environment characterized by placental ischemia and oxidative stress. In the second stage, the consequent release of cytokines, such as sFlt-1, into the maternal circulation that induces a systemic response in the preeclamptic patient. Reprinted from Steegers et al. [16]. 


\subsection{Markers of vascular and endothelial dysfunction in pre-eclampsia}

\subsubsection{Imbalance of angiogenic mediators}

A pregnancy complicated by PE implicates an anti-angiogenic state. Placentas of women with PE revealed an overexpression of sFLT-1, a soluble receptor for the angiogenic factors, VEGF and placental growth factor [17]. More specifically, the growth factor VEGF stimulates angiogenesis and maintains endothelial integrity. sFlt-1 acts as an antagonist of VEGF and placental growth factor by binding and sequestering these growth factors from interacting with their receptors [17]. sFlt-1 has also been shown to be elevated weeks before clinical manifestations of PE were evident, indicating a role in the pathogenesis and prediction of PE [18]. In addition, sFlt-1 has been shown to decrease cytotrophoblast invasion in vitro, indicating that an excess in placental sFlt-1 may contribute to the impaired trophoblast invasion and spiral artery remodeling observed in PE [19]. Additionally, an increase in both placental and circulating sFlt-1, as well as soluble endoglin, are associated with the development of the signs of PE, including hypertension and proteinuria [20]. The local imbalance of angiogenic mediators evidenced by an overproduction of anti-angiogenic factors suggests the maladaptive vascularization that occurs in the placenta of preeclamptic women. Since the increased levels of sFlt-1 decline back to normal following the delivery of the placenta, this indicates that the placenta may be the major source of this anti-angiogenic factor [18].

\subsubsection{Imbalance of coagulation factors}

There is an imbalance of anti-coagulation and pro-coagulation factors that serve as markers of endothelial dysfunction and has been reported in women who develop PE. These coagulation cascade factors include elevated levels of plasma thrombomodulin, fibronectin, and Von Willebrand factor [21]. Additionally, whole blood flow cytometry has revealed enhanced platelet activation and increased levels of platelet endothelial cell adhesion moleculae-1 (PCAM-1) in preeclamptic women [21]. Plasma levels of other adhesion cell molecules, such as vascular adhesion moleculae-1 (VCAM-1), intercellular adhesion molecule-1 (ICAM-1), and E-selectin, are also significantly elevated in preeclamptic women 
[21]. In addition, preeclamptic placentas display an increased frequency of placental infarcts [11] and altered morphology evidenced by abnormal cytotrophoblast proliferation and increased formation of syncytial knots. Further evidence for a key role of the placenta in the etiology of PE is the generally rapid recovery that patients experience following delivery [11,22].

\subsection{Maternal endothelial dysfunction and pre-eclampsia}

\subsubsection{Impaired uteroplacental perfusion}

The vascular endothelium is responsible for controlling smooth muscle tone by releasing vasoconstrictor and vasodilatory substances, as well as regulating anti-coagulation, anti-platelet, and fibrinolysis through the release of different soluble factors [21]. It has been suggested that placental ischemia leads to the release of placental factors that results in the endothelial dysfunction observed in the maternal circulation. Endothelial dysfunction is considered to underlie many of the manifestations of PE including hypertension, proteinuria, and edema [23]. Additionally, in women who develop PE, preexisting maternal factors such as chronic hypertension, diabetes, and hyperlipidemia may predispose the maternal endothelium to further damage [21]. Reduced placental perfusion is thought to be an initiating event in PE that leads to widespread dysfunction of the maternal vascular endothelium resulting in systemic hypertension [15]. Moreover, reduced perfusion to different organ systems gives rise to the classical symptoms and signs of PE: hypertension, proteinuria, edema, headache, scotomata, reduced glomerular filtration rate, and fetal growth restriction $[8,24]$.

\subsubsection{Endothelial function in preeclamptic and normotensive pregnancies}

In a case-control study to compare vascular endothelial function between women with previous $\mathrm{PE}$ and women with uncomplicated pregnancies at three months postpartum, vascular endothelial dysfunction was significantly different [25]. Brachial artery flow-mediated, endothelium-dependent dilation measures the vasodilatory response to increases in blood flow depending on the presence of a 
functionally intact endothelium [26]. This measure of dilation was lower in women with previous PE compared with controls [25]. The impaired endothelium-dependent flow-mediated dilation is more severe in women with recurrent PE compared with a single episode of PE. Since flow-mediated dilation is endothelium dependent [26], these results demonstrate that vascular endothelial function is impaired in women with previous PE [25].

\subsubsection{Endothelial dysfunction and the development of cardiovascular disease}

The vascular endothelium, a layer of squamous epithelial cells which lines the inside of blood and lymphatic vessels, plays a key role in the development of cardiovascular disease (CVD) [27]. Several cardiovascular diseases, such as heart failure, peripheral vascular disease, diabetes, and hypertension, are preceded by progressive loss of endothelial function [28]. The endothelial dysfunction leads to reduced vasodilatory ability; increased vascular permeability to biological toxins such as free radicals; reduced responses to ischemia which hinders the upregulation of angiogenic growth factors to enable vascular remodeling; and accelerated plaque formation [29]. Based on these findings, it is hypothesized that a significant contributor to maternal lifetime risk for CVD after PE is the persistence of endothelial dysfunction into the postpartum.

\subsection{Pre-eclampsia and future cardiovascular disease risk}

A pregnancy complicated by $\mathrm{PE}$ is associated with an elevated maternal lifetime risk for CVD, diabetes, and renal disease [30]. It is well established that women who have had a pregnancy complicated by PE are at increased risk of hypertension, ischemic heart disease, and premature cardiovascular death compared to women with normotensive pregnancies [31-33]. PE leads to a 4-fold increase in risk for chronic hypertension and 2-fold increase in stroke, venous thromboembolism, ischemic heart disease, and death [28]. Large epidemiologic studies have also demonstrated that women who have had PE are at 2fold risk to develop CVD later in life [34]. 


\subsubsection{Pre-eclampsia as a maternal placental syndrome}

Maternal placental syndromes (MPS) refer to hypertensive disorders of pregnancy and related placental abnormalities, such as PE, preterm birth, fetal growth restriction, placental abruption, and placental infarction [32]. PE is included in the MPS [32] that increase the risk of future CVD. The common mechanisms underlying MPS include impaired spiral arteries, placental ischemia, and endothelial dysfunction $[13,21,35]$. Ray et al. conducted a study which found that the future risk of CVD composite remained significant irrespective of the subtypes of MPS [32]. The future risk of CVD was also higher in women with traditional risk factors for CVD, including smoking and the individual and combined features of the metabolic syndrome [32]. These findings do not imply a causal relation between maternal placenta disorders in pregnancy and future CVD. Rather it relates to a woman's abnormal metabolic milieu that likely predates her pregnancy and continues after delivery [36]. This chronic state of dysmetabolism [36] might create an inhospitable environment during the development of the myometrial spiral arteries, which can adversely affect fetal health [37], while negatively affecting the macro and micro vessels of a woman's heart, brain, and extremities over a broader period of time.

\subsubsection{Risk factors for cardiovascular disease in women}

$\mathrm{PE}$ is associated with endothelial dysfunction and may be the initial event that triggers the development of atherosclerosis later in life [3]. Women with PE and women without complicated pregnancies have demonstrated differences in cardiovascular risk (CVR) factors including increased blood pressure, lipids, and body mass index (BMI), along with evidence of insulin resistance and residual microalbuminuria at various time points after delivery $[38,39]$. The presence of microalbuminuria years following a preeclamptic pregnancy $[40,41]$ may represent residual renal damage without overt renal dysfunction or early chronic kidney disease [42, 43] along with endothelial dysfunction [44].

One longitudinal prospective cohort comparing preeclamptic women and normotensive women reports differences in biochemical CVR factors at one year postpartum [30]. The data suggest that the 
development of PE may be one of the earliest identifiable risk markers of underlying CVR and potential future CVD in women. The risk for cardiovascular events increases with the number of CVR factors, including the presence of metabolic syndrome and microalbuminuria. Underlying CVR factors, such as those that make up the metabolic syndrome, likely play a major role in the development of PE [30]. These risk factors include increased blood pressure, total cholesterol, higher low-density lipoprotein cholesterol, triglycerides, increased BMI, fasting insulin, insulin resistance and microalbumin/creatinine ratio [30]. Moreover, PE and CVD share common risk factors, such as metabolic syndrome, and it is thought that these shared risk factors mediate the increased risk for hypertensive disorder of pregnancy and CVD at different times in a woman's life [45].

Sattar and Greer proposed that complications in pregnancy predispose mothers to later vascular and metabolic disease [46]. A key factor underlying CVD is the metabolic syndrome. Metabolic syndrome encompasses a spectrum of metabolic abnormalities associated with insulin resistance, which manifest as hyperglycemia, hyperlipidemia, and disturbance of coagulation [46]. The normal physiological response to pregnancy represents a transient state of metabolic syndrome in which several components are acquired, including a relative degree of insulin resistance, hyperlipidemia, and an increase in coagulation factors $[47,48]$. Normal pregnancy also involves upregulation of the inflammatory cascade and an increase in white cell count [49]. These metabolic changes of pregnancy are likely to be the result of hormonal changes, either direct or indirect, through regulation of early fat acquisition and its rapid mobilization in the second half of the gestational period [50]. Such metabolic responses could be considered as stress tests of maternal carbohydrate and lipid pathways and vascular function [46] that would normally resolve following delivery. In this way, adverse pregnancy outcome may be an indicator of increased risk of metabolic and vascular diseases later in life. 
Following a pregnancy complicated by PE, there is an increased prevalence of CVR factors [15]. It has been demonstrated that early onset PE leads to an increased risk of developing metabolic syndrome later in life compared to late onset PE [51]. Preeclamptic women also demonstrate altered endothelialdependent vascular function as compared with women with a history of healthy pregnancy, independently of maternal obesity, blood pressure, and metabolic disturbances associated with insulin resistance or dyslipidemia [24]. This pattern of metabolic or vascular changes in women with a history of PE is similar to the abnormalities seen in this condition at diagnosis, such as the exaggerated lipid and insulin levels, disturbed hemostatic factors, and endothelial dysfunction [50]. In addition, patients with PE have a tendency towards higher levels of triglycerides and low-density lipoprotein cholesterol, as well as longer persistence of insulin resistance postpartum compared to normotensive pregnancies [15].

\subsection{Pregnancy as a cardiovascular stress test}

Many of the women who experienced a preeclamptic pregnancy and have no signs of clinical disease following the pregnancy exhibit the phenotype of the metabolic syndrome, such as obesity, latent hypertension, dyslipidemia, insulin resistance, and hyperhomocysteinemia, as well as endothelial dysfunction at three to twelve months postpartum [52-55]. Additionally, the prevalence of metabolic syndrome was significantly greater in women who had PE than in controls at one and three years postpartum [56]. This study also showed higher risk ratios for metabolic syndrome in preeclamptic women than in healthy women at one and three years postpartum [56]. Women with the phenotype for metabolic syndrome and endothelial dysfunction prior to pregnancy introduces these women to additional metabolic and cardiovascular challenges of pregnancy itself that induces transient clinical disease (i.e. $\mathrm{PE})$ that resolves after pregnancy but is likely to re-emerge later in life as CVD $[46,57,58]$. 
Pregnancy is a cardiovascular stress test for the mother [58]. Rich-Edwards et al. represent the concept of pregnancy complications and the risk of future CVD (Figure 2) [59]. A normal, healthy woman, as shown by the green curve, will experience a transient increase in vascular dysfunction during her pregnancies, but not attain the arbitrary of vascular dysfunction associated with pregnancy complications. Into middle age, there are age-associated increases in vascular dysfunction and perhaps this woman will develop a vascular condition deeper into old age. In a complicated pregnancy, as shown by the red curve, the level of dysfunction surpasses the threshold for vascular dysfunction producing disease and the patient develops PE. The condition has a higher chance of reoccurring in a later pregnancy as well. In postpartum, this woman sets off on a trajectory that sees a larger, earlier increase in vascular dysfunction with age, and she is at risk of developing premature CVD.

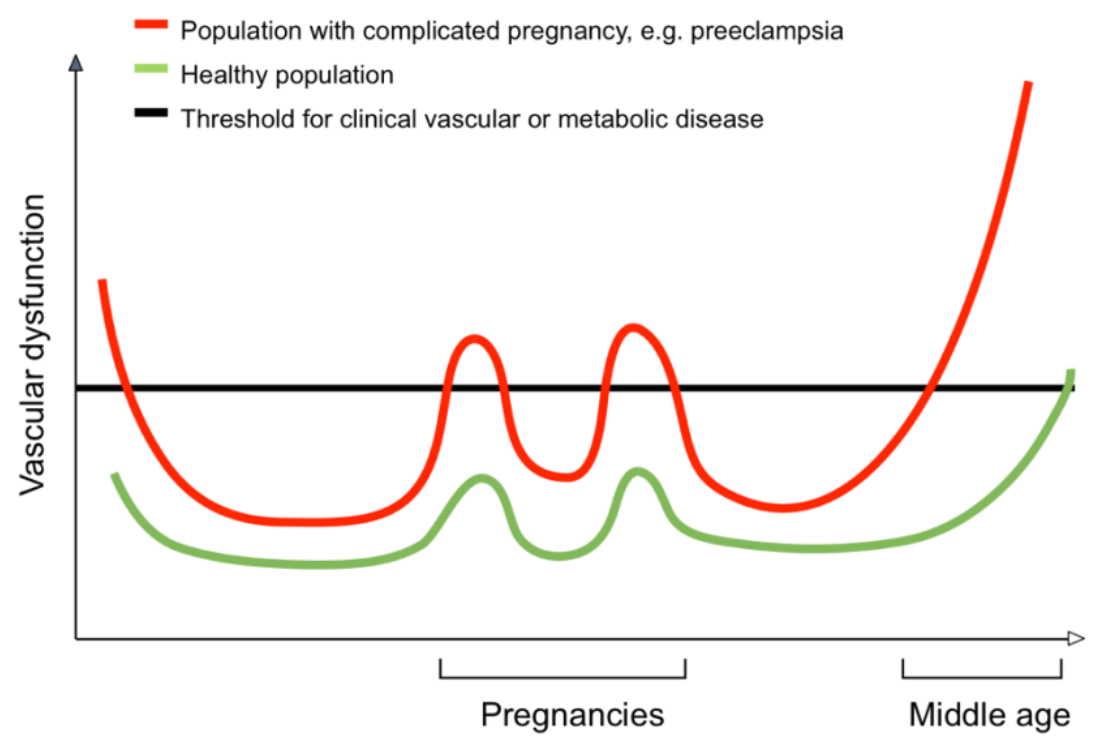

Rich-Edwards et al. Hypertension 2010;56:331-4

Figure 2: Vascular dysfunction in a normotensive pregnancy and a preeclamptic pregnancy. A pregnancy complicated by pre-eclampsia increases the risk of future vascular disease for the mother. The vascular dysfunction persists into the postpartum period following a preeclamptic pregnancy that predisposes the mother to cardiovascular disease. Reprinted from Rich-Edwards et al. [59] by permission of Wolters Kluwer Health, Inc. 


\subsection{Predictive value of the placenta}

\subsubsection{Placental development and fetal outcomes}

The placenta is a key organ that programs the fetus for health or disease later into adulthood [60]. The placenta regulates the transfer of nutrients to the fetus, therefore any disturbances in this flow plays a role in determining the disease risk in the offspring. The variations in the supply of nutrients to the fetus can change the genetic expression and permanently set the structure and function of the body [61]. Nutrition depends on the mother's metabolism and food reserves and on the placenta's ability to transfer nutrients from the mother to the baby [61]. Babies with a low birth weight are at risk of coronary heart disease [62]. This is thought to reflect fetal programming, the process whereby malnutrition in utero, and consequent small body size at birth, alters gene expression and leads to lifeline changes in the body's organs and systems [62].

\subsubsection{Placental morphometric measurements associated with elevated cardiovascular disease risk}

The placental function is reflected in its size and shape [63]. Placental size is one of the main features of the placenta that is associated with adult onset disease, such as heart failure and hypertension [64], hence the placental phenotype predicts postnatal disease in offspring. The weight of the placenta is important when compared to the fetal weight, which offers an insight into the developmental mechanisms that lead to disease beyond the predictive value of either birth weight or placental weight alone [64]. Consequently, the concept of placental efficiency has become more indicative of fetal and maternal health outcomes. Efficiency is defined as the ratio of placental weight to birth weight at any given stage of gestation but is usually applied at term [65].

The Helsinki Birth Cohort, comprising 20,431 men and women, has some of the most detailed information on the links between placental weight at birth and health through life into old age [66]. Martyn et al. showed that the highest risks for coronary heart disease has a placenta weight to birth weight (PW:BW) ratio that is less than $15 \%$ or greater than $22 \%$ [64]. This U-shaped variation shows that 
hypertension alone is predicted by low PW:BW ratio, whereas hypertension in combination with Type II Diabetes is predicted by a high PW:BW ratio [67]. A high ratio may indicate that the placenta has undergone a compensatory enlargement in response to fetal malnutrition [68], which is relevant in the process of assessing the efficiency of the placenta. Compensatory expansion maybe beneficial in some circumstances, to extract more nutrients from the mother, but if the compensation is inadequate and the fetus continues to be undernourished, the need to share its nutrients with an enlarged placenta may become a metabolic burden [68]. In contrast, a low PW:BW ratio, a small placenta bearing a large baby, may be indicative of a more efficient placenta.

The placental shape is described using its length and width. If the placenta is not perfectly round at delivery, it can be described by its longest axis and a perpendicular short axis [60]. These two axes, length and width, were measured on all placentas in Helsinki hospitals and are able to relate placental size and shape to fetal growth and disease conditions into adulthood. Although length and width are generally correlated, one dimension but not the other is often associated with a particular disease outcome or condition [60]. The specificity associated with the predictive value of disease provided by only a single placenta axis has been previously reviewed $[69,70]$. This led to the notion that the growth of the placental tissue along the two axes is controlled by different influences. It was hypothesized that tissue along the width serves as a nutrient sensor, responding to the mother's nutritional state and nutritional demands of the fetus, while the tissue along the length has different functions [68].

One study found that an increased width of the placenta alone was associated with increasing birth weight and the baby's head, chest, abdomen, and high circumferences [71]. In a separate study, having a shorter placental length, but not width, was associated with a shorter lifespan in men [72]. These findings suggest that the placental dimensions may act as predictive factors of CVD later on in life for the fetus. The Helsinki Birth Cohort examined the size of the baby, the length of gestation, and the weight of the placenta. The maximal length and diameter (width) of the placental surface were measured, with the 
difference between the two measurements used as a measurement of ovality [61]. The Helsinki cohort found that colorectal cancer was associated with a longer, more oval placental surface [61]. Additionally, placentas of babies born after preeclamptic pregnancies had a more oval-shaped surface that those from normotensive pregnancies [62]. The disrupted implantation that occurs in PE is associated with a reduced width, but not length, of the placenta, resulting in an oval-shaped surface [62]. Furthermore, a reduced width is associated with development of PE, coronary heart disease, chronic heart failure, hypertension, and lung cancer $[62,73-76]$. In contrast, placentas with reduced length were associated with reduced lifespan in men [72], as well as with an increased risk of asthma and Hodgkin's lymphoma [77, 78]. Based on these findings, it is thought that PE illustrates the effects of an extreme variation in the processes that regulates implantation.

$\mathrm{PE}$ is associated with a particular placental phenotype at birth [76] and has immediate and longterm consequences for the fetus [76, 79]. More specifically, PE is associated with reduced width and an oval surface [76]. An oval-shaped placenta may be a marker of fetal undernutrition throughout gestation. The shape of the placental surface is established around 8-12 weeks of gestation [80]. At implantation, after the embryonic trophoblast cells have invaded and remodeled the spiral arteries in the mother's uterine decidua, they plug the arteries to protect the early embryo from being damaged by the oxygen levels in the maternal blood [68]. At around 8 weeks, when the embryo is less susceptible to oxidative damage, the plugs are progressively removed [68]. This process begins on the periphery of what is at that stage a round placenta. If the process is initiated prematurely, due to the insufficient uterine secretions, the fetus is at risk of oxidative damage and the placenta becomes and remains oval in shape [68]. 


\subsection{Molecular and histopathology profiling and subclasses of pre-eclampsia}

\subsubsection{Subclasses of pre-eclampsia}

There is a lack of robust biomarkers and effective treatments for PE due to its multifactorial nature. Molecular and histopathology profiling techniques are a novel application that identified three subclasses of preeclamptic placentas, exhibiting distinct alterations in disease pathways and varying expressions of commonly accepted markers of PE [81]. Leavey et al. analyzed PE microarray studies and combined them with a new PE microarray data set that highlight clinical differences between subclasses of PE [83]. There were five placental clusters identified, however, only 3 clusters are related to preeclamptic etiologies [81]. The three subclasses of pre-eclampsia are: (1) "maternal” PE, (2) “canonical" PE, and (3) "immunologic" PE. This classification of PE can identify the women who belong to the "canonical" PE subclass, who are at highest risk of future CVD.

A gene-set enrichment analysis (GSEA) was applied to the combined set of samples to characterize the different clusters at a molecular level. Cluster 1 ("maternal” PE) preeclamptic samples were predominantly placentas from term and near-term delivery with known maternal risk factors of nulliparity or a previous hypertensive pregnancy [83]. The development of PE in cluster 1 was likely due to common risk factors or persistent endothelial damage from a previous pregnancy $[24,84]$ that indicate an underlying susceptibility to maternal CVD [81]. Cluster 2 (“canonical” PE) samples were highly enriched in PE and demonstrated the highest expression of the known markers for PE, fms-like tyrosine kinase 1 (FLT1) and endoglin (ENG) [82]. In addition, cluster 2 samples demonstrated smaller placental weights, early deliveries, and coexisting diagnoses of intrauterine growth restriction (IUGR) and HELLP syndrome [82]. Histological examination of the PE-IUGR samples from cluster 2 revealed distal villous hypoplasia, placental infarctions, and syncytial knots [81]. GSEA identified increased hypoxia and response to nutrients [85-90], supporting that the pathogenesis of PE in this cluster is of placental origin [83]. Cluster 3 ("immunologic" PE) is another molecular group of preeclamptic samples with a severe 
form of the pathology, including IUGR. The GSEA and histopathologic analysis of samples in cluster 3 identified an increased expression of immune response genes and poor maternal tolerance [91] of the fetoplacental unit. Furthermore, the majority of the women in cluster 3 who had experienced PE were A blood type [82], which is associated with an increase in inflammatory markers [92]. In contrast, the women in cluster 3 who did not experience PE were all B blood type [82], which has not been linked to this increased risk of PE [92], and thus may be immunologically protective toward the development of symptoms in the mother [82].

\subsubsection{Discriminatory potential of genetic biomarkers between placental clusters}

Leavey et al. have identified a small panel of candidate markers that are able to discriminate between the observed placental clusters for validation by quantitative polymerase chain reaction (qPCR) [82]. The preeclamptic samples in cluster 2 expressed the highest levels of FLT1 and ENG and could be easily distinguished from all the assessed non-preeclamptic samples using only these two genes. Upon further assessment of discriminatory potential between the clusters, there were 3 markers that distinguish the clusters. LIM and calponin homology domains 1 (LIMCH1), follistatin-like 3 (FSTL3), and transporter 1, ATP-binding cassette, subfamily B (TAPl) as the genes with the most discriminatory potential [82]. These three genes provided enough information to successfully assign the placental samples to their clusters in the majority (approximately 85\%) of cases [82]. Overall, the molecular and histopathological profiling of placental tissue offers insight into the placental heterogeneity observed in PE. The subclassification of PE based on genetic biomarkers allows for the development of etiologybased treatments aimed at specific subclasses of this disorder. 


\subsection{Rationale, Hypothesis, and Objective}

\subsubsection{Rationale}

It is unclear why women with certain pregnancy complications, like PE are at risk for future CVD. It is unclear whether PE serves as an independent obstetrical risk factor for CVD, or if pre-existing CVR factors which predispose women to PE is the culprit. An improved understanding of any changes in CVR profile that are associated with PE in pregnancy will allow for improved detection of women at highest risk for CVD postpartum. Identifying the mothers who are at-risk early on will allow clinicians to initiate postpartum interventions and limit future disease burden. Using the PW:BW ratio, along with the genetic biomarkers and histopathology profiling, may be a useful screening method at the time of delivery to stratify patients by their risk of future disease and determine which women should undergo further cardiovascular screening postpartum. It is well-established that women who experienced PE are at increased risk of hypertension, ischemic heart disease, and premature cardiovascular death compared to women is normotensive pregnancies. We believe that the placental morphology may be a marker of future maternal CVD risk. The altered PW:BW ratio, length and width measurements, and genetic biomarkers and histopathology of placental tissue may be indicative of a woman's abnormal metabolic milieu that predates her pregnancy and continues after delivery.

\subsubsection{Hypothesis}

We hypothesize that the assessment of placental morphology will identify women with PE who should undergo CVR screening postpartum. A high and low PW:BW ratio, as well as a placenta with a reduced width are hypothesized to be indicative of high-risk women for postpartum CVR screening.

\subsubsection{Research Objective}

The objective of this study is to determine if placental weight, length, and width could identify which women with PE should be screened for CVR factors which increase the risk of future CVD. 


\section{Chapter 2}

\subsection{Introduction}

A pregnancy complicated by PE is associated with an elevated maternal lifetime risk for CVD diabetes, and renal disease [30]. The condition has also been associated with an adverse postpartum blood lipid profile, increased albuminuria, decreased insulin sensitivity and hyperglycemia [93-95]. Certain pregnancy-related complications, which include PE, can identify women with underlying CVR, which if left unrecognized, can lead to the development of CVD later in life [96]. The use of pregnancy-related complications alone as a screening tool selects a clinical population of concern, however only half of these women will demonstrate high lifetime CVD risk profiles when screened in the postpartum period [97]. Additionally, metabolic syndrome is a composite of CVR and an underlying risk factor for CVD, which when present, increases the risk of developing CVD or Type II Diabetes Mellitus [46, 98]. Increased insulin resistance is one of the components of metabolic syndrome, which is well established to be associated with PE [99]. As such, the identification of additional screening tools that could be used to better identify the subset of women at highest-risk, specifically during the pre-/peri-natal period, is warranted.

The placenta is known to play an important mediating role in fetal programming of lifetime chronic diseases [60]. Placental size and morphology measurements, taken at birth, have been shown to be associated with several adult chronic diseases in large population-based studies, including hypertension, colorectal cancer, and coronary heart disease in offspring $[61,62,64]$. The size of the placenta relative to the fetal size may offer insight into the developmental mechanisms that lead to disease beyond the predictive value of either birth weight or placental weight alone [64]. The placenta has been shown to influence birth weight and is directly correlated with birth weight [100]. Therefore, the PW:BW 
ratio has been extensively studied to determine its association with long-term adverse neonatal/child outcomes [100].

The physiological mechanisms underpinning the association between the development of PE and lifetime CVD risk are not well understood. It is unclear whether pre-existing CVR factors, vascular damage resulting from a PE pregnancy itself, or a combination of both predispose women to future CVD. However, what is clear is that early identification and intervention could improve health outcomes for these women [97]. The pre- and peri-natal window offers a unique opportunity to screen and identify those highest risk women, as during this time women have increased interaction with the health care system and demonstrate considerable motivation to initiate lifestyle interventions if necessary. As such, efforts to identify clinically identifiable markers to determine which women with pregnancy complications are at likely to be at high risk of future CVD would lead to effective and cost-efficient methods of patient risk stratification for cardiovascular health screening in the postpartum period.

Considering the placenta is the vital organ of pregnancy and known to play an integral role in the establishment and progression of PE, it is logical to determine if basic placental measurements, easily obtained at the time of delivery, may serve as a useful marker to identify which women have underlying risk factors and should undergo CVD risk screening. The objective of this study was to determine if placental morphology could predict which women with PE are most likely to have underlying CVR factors and are at greatest risk of future CVD, and whether these simple measurements could be used to triage high-risk women for postpartum CVR screening. 


\subsection{Methods}

\subsubsection{Patient selection}

This study was reviewed for ethical compliance by the Queen's University and Affiliated Teaching Hospitals Health Science Research Ethics Board (OBGY-340-18). At the Kingston Health Sciences Centre (KHSC), women who experience pregnancy complications, including PE, are referred to the Maternal Health Clinic (MHC) for postpartum CVR screening at six months postpartum [97]. Women were eligible for inclusion in the current study if they attended the MHC from November 2011 to December 2017, were diagnosed with PE during the index pregnancy, and had a least one placental morphology measurement available. Women were excluded if they had a twin pregnancy or did not have any placental measurements available. Although the collection of placental measurements is considered standard of care at the KHSC, some of these values were missing in the delivery record and/or pathology reports.

A diagnosis of PE and severity of disease was defined according to the criteria of The American College of Obstetricians and Gynecologists [101]. Patients were categorized as having severe PE if they had a systolic blood pressure of $160 \mathrm{mmHg}$ or higher, a diastolic blood pressure of $110 \mathrm{mmHg}$ or higher and/or HELLP syndrome. Patients met the criteria for HELLP syndrome if they presented with hemolysis (serum lactate dehydrogenase $\geq 600 \mathrm{U} / \mathrm{L}$ ), elevated liver enzymes (serum aspartate aminotransferase $\geq 70$ U/L), and low platelet count $(<100,000 / \mu \mathrm{L})[102]$. Maternal and fetal/neonate demographics and clinical information, including maternal blood pressure and biochemical measurements, were extracted from the electronic birth record. 


\subsubsection{Placental morphometric measurements}

At the KHSC, it is standard of care for every patient to have measurements of placental weight, length, and width, regardless of pregnancy outcome. All placental measurements were abstracted from either pathology reports or electronic birth records. PW:BW ratios were calculated and categorized into three groups: (1) PW:BW ratio of less than $15 \%$, (2) $15.0 \%$ to $19.9 \%$, and (3) $20 \%$ or greater. These categories were chose based on a previous study that showed that the highest risk for coronary heart disease has a PW:BW ratio that is less than $15 \%$ or greater than $22 \%$, represented by a U-shaped variation with adverse health outcomes at the upper and lower extremes [64]. The threshold of $20 \%$ was used since there was a greater correlation between underlying CVR and the lower extreme of the PW:BW ratio and $20 \%$ was the greatest predictive value for lifetime CVR. Additionally, the percentile of PW:BW adjusted for fetal sex and gestational age was considered $[103,104]$. Deliveries with a PW:BW ratio below the $10^{\text {th }}$ percentile were considered to comprise the low PW:BW ratio, and those with PW:BW ratio above the $90^{\text {th }}$ percentile were considered to comprise the high PW:BW group as previously described in the literature [105]. The remaining deliveries were used as the reference group with a normal PW:BW ratio.

\subsubsection{Lifetime cardiovascular disease risk estimation}

Maternal postpartum clinical and biochemical CVR measurements were extracted from the MHC database. Using the following extracted measurements, each woman was assigned a lifetime CVD risk score, as previously described [106]: total cholesterol, systolic blood pressure, diastolic blood pressure, fasting glucose or diagnosis of Type I or Type II Diabetes, and smoking status. As detailed previously, women were considered as "high-risk" if their estimated lifetime CVD risk score was $\geq 39 \%$, a value in excess of baseline risk estimated for a healthy adult female population. High vs. low lifetime CVD risk profiles were used as the primary outcome of interest in the current analysis. 


\subsubsection{Data analysis}

Bivariate association to lifetime CVD risk category (high vs. low) were carried out using independent samples t-test, with continuous variables of interest including placental length, width, weight, and the PW:BW ratio. Mann-Whitney U test was used for the non-normally distributed data and a Chi-square test was used for categorical data. A multivariable logistic regression model was built to examine the relationship between placenta morphology and lifetime CVD risk estimation at six months postpartum, including maternal variables such as maternal age, pre-pregnancy BMI, gestational age at delivery, and severity of PE (mild or severe). Data are presented as odds ratios with $95 \%$ confidence intervals. Summary statistics are presented as mean (Standard Deviation (SD)), counts (percentages), and median (Interquartile Range (IQR). A p-value of $<0.05$ was deemed statistically significant. SPSS Version 25 was used for analysis.

\subsection{Results}

\subsubsection{Patient demographics}

Out of the 12,012 deliveries between May 2011 and June 2017, 1,293 had a relevant complication and were invited to attend the MHC. Of these women, 638 attended their appointment. Of those, 216 women were diagnosed with PE in their most recent pregnancy (Figure 3). After excluding twin pregnancies and pregnancies without placental measurements, 186 participants remained. The baseline characteristics of the 186 preeclamptic women, with a gestational age range of 23 to 42 weeks, are presented in Table 1. 


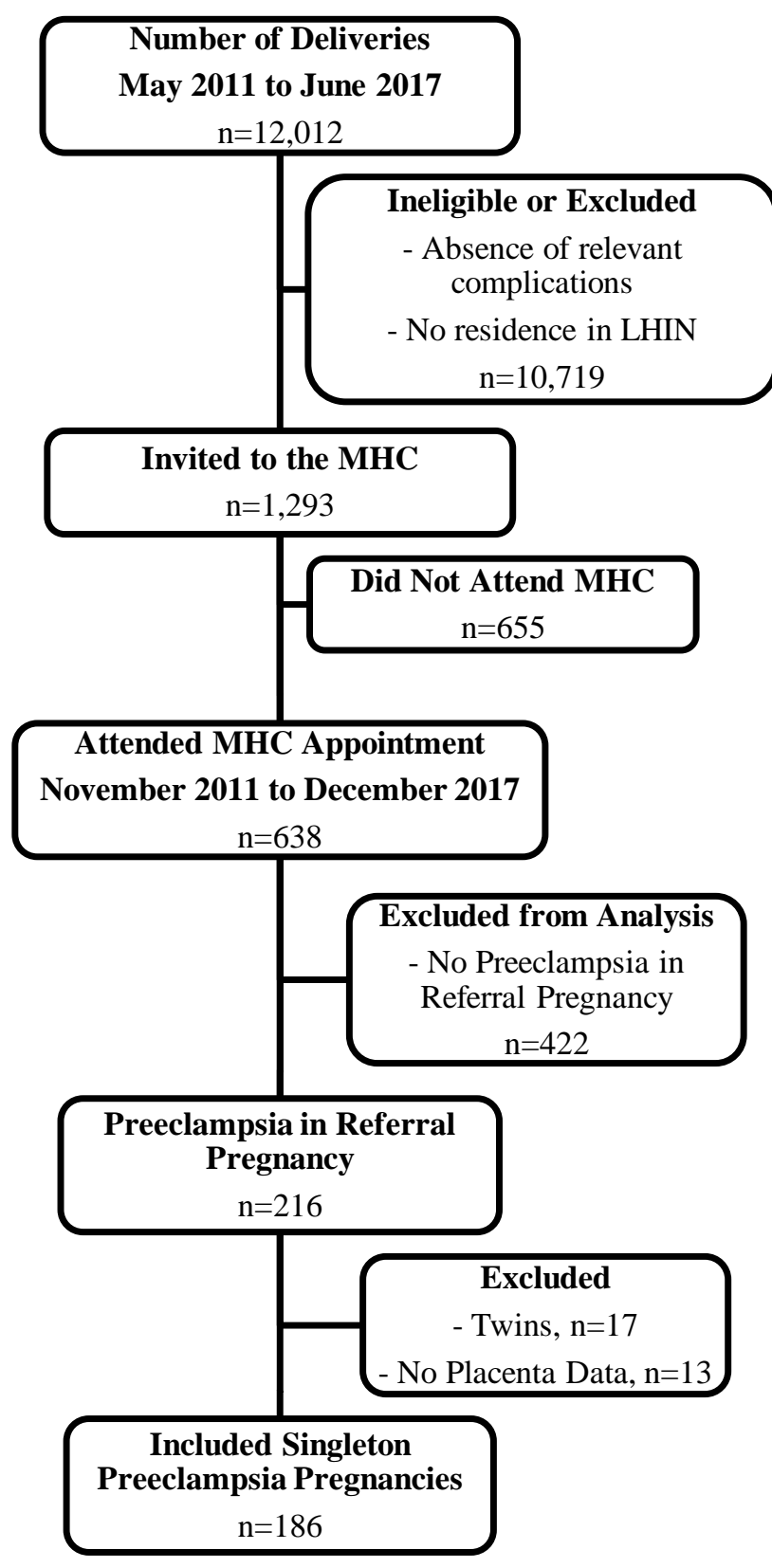

Figure 3: Inclusion criteria for study participants. Flow chart diagram of eligible study participants which included 186 singleton preeclamptic women with at least one placental measurement available. 
Table 1: Maternal clinical characteristics and their lifetime cardiovascular disease risk profiles calculated at 6 months postpartum. Data presented as mean (SD) if normally distributed data, as median [IQR] if not normally distributed data, and as number (\%) if categorical.

All Participants B B CVD Risk Category

\begin{tabular}{|c|c|c|c|c|}
\hline & $\mathrm{N}=186$ & $\begin{array}{l}\text { High Risk } \\
\mathrm{N}=85\end{array}$ & $\begin{array}{l}\text { Low Risk } \\
\mathrm{N}=76\end{array}$ & P-Value \\
\hline \multicolumn{5}{|l|}{ Maternal Age (years) } \\
\hline Mean (SD) & $31.4(5.5)$ & $32.1(5.5)$ & $30.9(5.4)$ & 0.19 \\
\hline \multicolumn{5}{|l|}{$\operatorname{BMI}\left(\mathrm{kg} / \mathrm{m}^{2}\right)$} \\
\hline Median [IQR] & $26.2[22.4-31.5]$ & $27.7[23.4-32.0]$ & $24.7[21.2-28.6]$ & $0.008^{*}$ \\
\hline Unknown & 1 & 0 & 1 & \\
\hline \multicolumn{5}{|l|}{ Race, n (\%) } \\
\hline Caucasian & $166(91.2)$ & $77(91.7)$ & $66(89.2)$ & 0.61 \\
\hline Other & $16(8.8)$ & $7(8.3)$ & $8(10.8)$ & \\
\hline Unknown & 4 & 1 & 2 & \\
\hline \multicolumn{5}{|l|}{ Education, n (\%) } \\
\hline University or College Complete & $152(92.6)$ & $70(83.3)$ & $67(89.3)$ & 0.28 \\
\hline Some University or College & $13(7.1)$ & $5(6.0)$ & $5(6.7)$ & \\
\hline High School or Less & $19(10.3)$ & $9(10.7)$ & $3(4.0)$ & \\
\hline Unknown & 2 & 1 & 1 & \\
\hline \multicolumn{5}{|l|}{ Income, n (\%) } \\
\hline$\geq \$ 90,000$ & $78(45.3)$ & $34(44.2)$ & $37(51.4)$ & 0.46 \\
\hline$\$ 60-89,000$ & $48(27.9)$ & $20(26.0)$ & $21(29.2)$ & \\
\hline$\$ 30-59,000$ & $30(17.4)$ & $14(18.2)$ & $10(13.9)$ & \\
\hline$<\$ 30,000$ & $16(9.3)$ & $9(11.7)$ & $4(5.6)$ & \\
\hline Unknown & 14 & 8 & 4 & \\
\hline \multicolumn{5}{|l|}{ Smoking, n (\%) } \\
\hline Yes & $15(8.1)$ & $11(12.9)$ & 0 & $0.001^{*}$ \\
\hline No & $171(91.9)$ & $74(87.1)$ & $76(100.0)$ & \\
\hline \multicolumn{5}{|l|}{ Lifetime CVD Risk, n (\%) } \\
\hline All Optimal & $31(19.3)$ & 0 & $31(40.8)$ & $<0.001 *$ \\
\hline One or More Not Optimal & $45(28.0)$ & 0 & $45(59.2)$ & \\
\hline One or More Elevated & $47(29.2)$ & $47(55.3)$ & 0 & \\
\hline 1 Major & $24(14.9)$ & $24(28.2)$ & 0 & \\
\hline 2 or More Major & $14(8.7)$ & $14(16.5)$ & 0 & \\
\hline Unknown & 25 & 0 & 0 & \\
\hline \multicolumn{5}{|l|}{ Metabolic Syndrome, n (\%) } \\
\hline Yes & $32(19.9)$ & $27(31.8)$ & $5(6.6)$ & $<0.001 *$ \\
\hline No & $129(80.1)$ & $58(68.2)$ & $71(93.4)$ & \\
\hline Unknown & 25 & 0 & 0 & \\
\hline
\end{tabular}


The median maternal pre-pregnancy BMI for the women at high risk for future CVD was higher than the women at low risk, with a median BMI of $27.7 \mathrm{~kg} / \mathrm{m}^{2}$ and $24.7 \mathrm{~kg} / \mathrm{m}^{2}$, respectively. Similarly, women who were diagnosed with metabolic syndrome had an elevated BMI in comparison to women who were not diagnosed with metabolic syndrome, with a median BMI of $33.9 \mathrm{~kg} / \mathrm{m}^{2}$ and $24.6 \mathrm{~kg} / \mathrm{m}^{2}$, respectively. Additionally, none of the low-risk individuals were smokers, in comparison with $12.9 \%$ of high-risk individuals.

\subsubsection{Placental morphology measurements and postpartum lifetime cardiovascular disease risk estimation}

Across the whole cohort mean placental length and width were $18.8 \pm 3.3 \mathrm{~cm}, 15.7 \pm 3.0 \mathrm{~cm}$, respectively (Table 2$)$. 
Table 2: Placental morphometric measurements and fetal birth weight collected at the time of delivery. Data presented as mean (SD) if normally distributed data and as number (\%) if categorical.

$$
\mathrm{N}=186
$$

Placental Weight (g)

$\begin{array}{cc}\text { Mean (SD) } & 503.2(187.3) \\ \text { Unknown } & 2\end{array}$

Ratio of Placental Weight to Birth

Weight (\%)

$\begin{array}{rc}\text { Mean (SD) } & 18.2(4.4) \\ \text { Unknown } & 4\end{array}$

Ratio of Placental Weight to Birth

Weight (\%), n (\%)

$\begin{array}{rc}<15.0 & 35(19.2) \\ 15.0-19.9 & 103(56.6) \\ \geq 20.0 & 44(24.2) \\ \text { Unknown } & 4\end{array}$

Placental Length $(\mathrm{cm})$

$\begin{array}{rc}\text { Mean (SD) } & 18.8(3.3) \\ \text { Unknown } & 1\end{array}$

Placental Width (cm)

$\begin{array}{rc}\text { Mean (SD) } & 15.7(3.0) \\ \text { Unknown } & 1\end{array}$

Ratio of Placental Length to Width

$\begin{array}{cc}\text { Mean (SD) } & 122.3(26.6) \\ \text { Unknown } & 1\end{array}$

Shape, n (\%)

$\begin{array}{rc}\text { Round } & 24(32.4) \\ \text { Oval } & 32(43.2) \\ \text { Irregular } & 18(24.4) \\ \text { Unknown } & 112\end{array}$

Infarct, n (\%)

$\begin{array}{ll}\text { Yes } & 36(49.3) \\ \text { No } & 37(50.7)\end{array}$

Unknown 113 
No differences in these two measurements were observed between high and low lifetime CVD risk groups. Additionally, $43.2 \%$ of the placentas with recorded shapes were oval, a phenotype of a preeclamptic placenta, and $49.3 \%$ of the placentas exhibited placental infarcts (Table 2). Across the entire cohort, the mean PW:BW ratio was $18.2 \pm 4.4 \%$ (Table 2 ) and when compared directly, no differences in the morphology variables were observed between lifetime CVD risk groups (Table 3). 
Table 3: Placental measurements according to lifetime cardiovascular disease risk profiles calculated at 6 months postpartum. Data presented as mean (SD) if normally distributed data and as number $(\%)$ if categorical.

By CVD Risk Category

\begin{tabular}{|c|c|c|c|}
\hline & High Risk & Low Risk & P-Value \\
\hline & $\mathrm{N}=85$ & $\mathrm{~N}=76$ & \\
\hline \multicolumn{4}{|l|}{ Placental Weight (grams) } \\
\hline Mean (SD) & $477.1(182.7)$ & $511.9(193.7)$ & 0.25 \\
\hline Unknown & 1 & 1 & \\
\hline \multicolumn{4}{|l|}{ Neonatal Weight (grams) } \\
\hline Mean (SD) & $2766.9(1020.0)$ & $2842.1(926.6)$ & 0.15 \\
\hline Unknown & 1 & 1 & \\
\hline \multicolumn{4}{|l|}{ Ratio Placental Weight to Birth Weight } \\
\hline Mean (SD) & $18.0(4.0)$ & $18.3(5.1)$ & 0.67 \\
\hline Unknown & 2 & 2 & \\
\hline \multicolumn{4}{|l|}{ Ratio Placental Weight to Birth Weight } \\
\hline$<15.0 \%$ & $19(22.9)$ & $12(16.2)$ & \\
\hline $15.0-19.9 \%$ & $48(57.8)$ & $41(55.4)$ & 0.32 \\
\hline$\geq 20.0 \%$ & $16(19.3)$ & $21(28.4)$ & \\
\hline Unknown & 2 & 2 & \\
\hline \multicolumn{4}{|l|}{ Placental Length (cm) } \\
\hline Mean (SD) & $18.7(3.3)$ & $18.8(3.4)$ & 0.87 \\
\hline Unknown & 0 & 0 & \\
\hline \multicolumn{4}{|l|}{ Placental Width (cm) } \\
\hline Mean (SD) & $15.4(2.7)$ & $16.0(3.4)$ & 0.22 \\
\hline Unknown & 0 & 0 & \\
\hline \multicolumn{4}{|l|}{ Ratio of Placental Length to Width } \\
\hline Mean (SD) & $1.23(0.17)$ & $1.22(0.37)$ & 0.94 \\
\hline Unknown & 0 & 0 & \\
\hline \multicolumn{4}{|l|}{ Placental Weight Centile } \\
\hline Mean (SD) & $66.1(38.1)$ & $67.3(37.6)$ & 0.85 \\
\hline Unknown & 4 & 7 & \\
\hline \multicolumn{4}{|l|}{ Placental Weight Centile } \\
\hline$\leq 10^{\text {th }}, \mathrm{n}(\%)$ & $13(16.0)$ & $10(14.5)$ & 0.96 \\
\hline $11-89^{\text {th }}, \mathrm{n}(\%)$ & $27(33.3)$ & $24(34.8)$ & \\
\hline$\geq 90^{\text {th }}, \mathrm{n}(\%)$ & $41(50.6)$ & $35(50.7)$ & \\
\hline Unknown & 4 & 7 & \\
\hline
\end{tabular}


However, when a multivariable model was used to adjust for maternal age, pre-pregnancy BMI, gestational age at delivery, and severity of PE (mild or severe), having a lower PW:BW ratio was associated with high lifetime CVD risk screening at six months postpartum (Table 4).

Table 4: Logistic regression models for high lifetime cardiovascular disease risk. Adjusted for maternal age, pre-pregnancy BMI, gestational age at delivery, severity of PE (mild or severe).

$* \mathrm{p}<0.05$

High Lifetime Risk

Unadjusted Models

N Odds Ratio $\quad 95 \%$ CI

P-Value

\section{Model 1}

Ratio Placental Weight to Birth Weight (\%)

157

0.99

$0.92-1.06$

0.67

Ratio Placental Weight to Birth Weight $<15.0 \%$

Ratio Placental Weight to Birth Weight 15-19.9\%

Ratio Placental Weight to Birth Weight $>20.0 \%$

32

87

38

$\begin{array}{cc}2.06 & 0.79-5.38 \\ 1.39 & 0.65-2.98 \\ \text { Reference } & -\end{array}$

Model 3

Placental Weight Centile (\%)

150

$1.000 .99-1.01$

154

0.11

Model 4
$0.79-5.38$

0.85

0.14
0.40
-

-

32

38

148

$0.47-1.96$

0.91 
Women at the lowest range of PW:BW ratios $(<15.0 \%)$ demonstrated the highest odds for lifetime CVD risk $($ Odds Ratio $(\mathrm{OR})=4.49, \mathrm{p}<0.009)$, while women with a PW:BW ratio between $15.0-19.9 \%$ also demonstrated elevated odds for lifetime CVD risk $(\mathrm{OR}=2.80, \mathrm{p}<0.03)$. The sensitivity of a PW:BW less than $20 \%$ to high lifetime risk for CVD is $80.7 \%$, while the specificity is $28.4 \%$.

\subsection{Discussion}

Following a preeclamptic pregnancy, a woman is at elevated risk for CVD across their lifetime, prompting the establishment of postpartum CVR screening clinics. However, approximately half of the women screened at six months postpartum at these clinics demonstrate no evidence of elevated risk (no elevations in measured risk factors) [97]. Therefore, ways to better identify and triage who should be sent for postpartum CVR screening is warranted. In the current study, we sought to determine if simple placental measurements routinely taken at the time of delivery could be useful in identifying those women at highest risk, who would benefit most from postpartum screening and intervention. While direct comparisons of basic placental morphology measurements alone were not associated with CVR profiles postpartum, adjusted multivariable modeling of the data indicate that women with low PW:BW ratios, particularly at the extreme $(<15 \%)$, were more likely to screen as high risk for lifetime cardiovascular events when screened in the postpartum period. These simple measurements may confer clinical utility in identifying "high-risk" patients at the time of delivery.

It is well-established that women who have had a pregnancy complicated by PE are at increased risk of hypertension, ischemic heart disease, and premature cardiovascular death compared to women with normotensive pregnancies [31-33]. More specifically, PE is associated with endothelial damage which may be the initial event that that triggers the development of atherosclerosis later in life [3]. Additionally, in women who develop PE, pre-existing maternal factors such as chronic hypertension, diabetes, and hyperlipidemia may predispose the maternal endothelium to further damage [21]. 
PE has been labeled as MPS [32] that increases the risk of future CVD. The future risk of CVD was found to be higher in women with traditional risk factors for CVD, including smoking and the individual and combined features of the metabolic syndrome [24]. These findings do not imply a causal relation between maternal placenta disorders in pregnancy and future CVD. Rather, it relates to a woman's abnormal metabolic milieu that predates her pregnancy and continues after delivery [36]. This chronic state of dysmetabolism [36] might create an inhospitable environment during the development of the placental spiral arteries, which can adversely affect fetal health [37], while negatively affecting the large arteries of a woman's heart, brain, and extremities over a broader period of time [32].

Women who have had a pregnancy complicated by PE have a greater prevalence of CVR factors compared to a normotensive pregnancy. The metabolic or vascular changes in women with a history of $\mathrm{PE}$ are reflected in the elevated lipid and insulin levels, altered hemostatic factors, and endothelial dysfunction. The multifactorial nature of PE implicates the release of placental and circulating antiangiogenic factors that suggest the maladaptive vascularization that occurs in the placenta of preeclamptic women. As such, we believe that the measurements of placental morphology may be an additional marker of future maternal CVD risk. The altered PW:BW ratio, may be indictive of a woman's abnormal metabolic milieu that predates her pregnancy and continues after delivery. The placenta may be an additional marker in identifying the mothers who are at-risk early on that will allow clinicians to initiate postpartum interventions and limit future disease burden.

In the present study, we have identified low PW:BW ratios as a simple clinical measure that may be useful in identifying women with underlying CVR factors and have high lifetime CVD risk profiles following a preeclamptic pregnancy, who would benefit most from postpartum CVR screening and intervention. While further study is required to validate the utility and generalizability of the measure, early identification of CVR factors would allow for early intervention with personalized therapies and preventive programs. The next step would involve conducting a prospective validation study in which we 
would include women with and without pregnancy complications. Approximately $17 \%$ of women in the MHC who do not have pregnancy complications would be found to be at high risk of CVD, identifying a subgroup of women with normotensive pregnancies who should undergo CVR screening postpartum. In those women who are exposed and unexposed to PE, the study would determine if the placental morphometric measurements would predict who is at higher risk for CVD at six months postpartum. 


\section{Chapter 3}

\section{General Discussion}

\subsection{Pre-eclampsia and future cardiovascular disease risk}

A pregnancy complicated by PE is associated with an elevated lifetime risk for CVD. It is wellestablished that women who have experienced a preeclamptic pregnancy are at 4-fold increase risk of chronic hypertension and 2-fold increase in stroke, venous thromboembolism, ischemic heart disease, and cardiovascular death [28]. Therefore, pregnancy complications like the development of PE afford the opportunity for postpartum risk screening to facilitate lifestyle modification, and potentially therapeutic intervention, to reduce the risk of future disease. However, not all women who develop PE are at increased risk of future CVD so better ways to identify who should be screened postpartum are needed. Further, a small number of women with uncomplicated pregnancies are also at future CVD risk. Given that the development of PE is in large part due to impaired placental function, placental assessment at the time of delivery could identify the women who are at a high risk for CVD postpartum, and therefore allow for better identification of those who should be screened.

\subsubsection{The predictive value of placenta weight to birth weight ratio and the risk of lifetime cardiovascular disease}

Our data demonstrates a relation between a low PW:BW ratio and higher lifetime CVD risk. The preeclamptic women were categorized into three groups of $\mathrm{PW}: \mathrm{BW}$ ratios, with the greatest association with increased lifetime risk of CVD at PW:BW ratio of less than $15 \%$. In the multivariable logistic

regression model adjusted for maternal age, pre-pregnancy BMI, gestational age at delivery, and severity of PE, women with a PW:BW ratio of less than $15 \%$ were 4.49 times more likely to be found at the time of six month postpartum screening to have a high lifetime risk of future CVD. Women with a PW:BW ratio of $15.0-19.9 \%$ were 2.80 times more likely to have high lifetime risk of CVD. If a PW:BW ratio of less than 20\% is test positive for future CVD risk and a PW:BW ratio of greater than $20 \%$ is test negative, the sensitivity is high ( $80.7 \%$ [95\% CI: $0.70-0.88]$ ), and the specificity is low (28.4\% [95\% CI: 0.19 - 
0.40]). For a highly sensitive test, a negative result rules out the disease. If the PW:BW ratio cut-off to be test positive is less than $15 \%$, the test sensitivity is low (22.9\% [95\% CI: $0.15-0.34])$ and the specificity is high (83.8\% [95\% CI: 0.73-0.91]). A positive test with high specificity rules in the disease. This study indicates that a PW:BW of less than $15 \%$ is highly specific, reducing the number of false positives and correctly identifying who is at highest risk of future CVD if positive. However, an ideal test should be highly sensitive and reduce the number of false negatives so that the women with uncomplicated pregnancies who are at high risk of CVD are identified.

Approximately $18 \%$ of women with uncomplicated pregnancies are found to be at high lifetime risk of CVD if screened at six months postpartum. It is unknown if these women are more likely to have a low PW:BW ratio. Therefore, a future prospective study of all women with a low PW:BW ratio may be useful in identifying all of the women, preeclamptics or normal pregnancy outcomes, that are at higher risk of future CVD. More specifically, all women who present with a PW:BW ratio of less than 15\% should receive postpartum follow-up in order to rule in the disease.

\subsubsection{The predictive value of placental weight to birth weight ratio and the risk of metabolic syndrome}

In the logistic regression model for metabolic syndrome as the outcome, the adjusted model to assess the association between PW:BW ratio and metabolic syndrome was not predictive. Insulin resistance, hyperlipidemia, and an increase in coagulation factors are metabolic changes which present as underlying CVR factors and likely play a role in the development of PE. Thirty-two out of the 186 preeclamptic women met the criteria for metabolic syndrome, 27 of which were significantly associated with a high lifetime risk for CVD. However, the current study did not show an association between placental morphometric measurements, specifically a low PW:BW ratio, and the diagnosis of metabolic syndrome at six months postpartum. This is likely because the metabolic syndrome does not appear to be related to placental morphology measurements or placental function. Metabolic syndrome alone may not be directly attributed to the alterations in placental development as seen in CVD. 


\subsubsection{The predictive value of placental length and width and the risk of lifetime cardiovascular disease risk}

The placental shape is described using its length and width, the longest axis and a perpendicular short axis, respectively [60]. It has been found that these two axes are able to relate placental shape to fetal growth and disease conditions into adulthood. Although the length and width are generally correlated, one dimension but not the other is often associated with a particular disease outcome or condition [60]. Our data collected from the electronic birth record and pathology reports show that $43.2 \%$ of the preeclamptic placentas were oval-shaped and $24.4 \%$ were irregular in shape. This indicated that a majority of the preeclamptic placentas at the time of delivery were not round, having unequal length and width measurements. This is supported by previous evidence that demonstrate that preeclamptic placenta is oval in shape with a reduced growth along its width, but not the length [62]. The growth of the placental tissue along the length and the width have been shown to be controlled by different influences [71]. It was first hypothesized by Kajantie et al. that the tissue along the width of placenta serves as a nutrient sensor in response to the mother's nutritional state and the nutritional demands of the fetus [76]. Based on our findings, the placental length, placental width, and the ratio of placental length to placental width did not correlate with the high risk vs. low risk women for lifetime CVD or metabolic syndrome.

\subsection{Future prospective validation study}

\subsubsection{Molecular and histopathology profiling}

A future prospective study will explore the relationship between placental measurements, genetic biomarkers, histopathologic placental lesions and the risk of CVD. Molecular and histopathology profiling for genes (Table 5) and placental histopathologic lesions (Table 6) with the aim of categorizing patients according to the pathology of disease will indicate specific subclasses of PE [82]. This will determine if there is an association with long-term CVD risk according to the type of PE a woman has. The previous study showed that a low PW:BW ratio was associated with an elevated lifetime risk of 
CVD, which warrants further investigation to see if the placental genes and/or histopathologic lesions will increase the predictive value of a PW:BW ratio of less than 20\%. Although a PW:BW ratio of less than $15 \%$ was more predictive of lifetime risk of $\mathrm{CVD}$, a PW:BW ratio of less than $20 \%$ indicated a higher test sensitivity, likely identifying more women with the risk of CVD and reducing the number of false negatives. At the time of delivery, the placental tissue of women with a PW:BW ratio of less than $20 \%$ will be collected from both healthy pregnancies and pregnancies complicated by PE. The goal would be to determine if the combination of molecular and histopathology profiling and $\mathrm{PW}: \mathrm{BW}$ ratio can better identify the women with uncomplicated and complicated pregnancies that are at highest risk for CVD. The placenta will be weighed and then sampled by taking four biopsies that are equidistant from the umbilical cord insertion, excluding the chorionic plate. Each biopsy will be placed into one of five test tubes so that each test tube has a sample of each quadrant. Following the sampling procedure, the tubes will be snap-frozen in liquid nitrogen and subsequently stored to extract mRNA for microarray analysis.

\begin{tabular}{|c|c|}
\hline Gene & Role of the gene \\
\hline$F L T 1^{*}$ & Highly expressed in PE \\
\hline$E N G^{*}$ & Highly expressed in PE \\
\hline $\operatorname{LIMCH} 1^{* *}$ & $\begin{array}{l}\text { Organization of actin skeleton, gene transcription, and RNA } \\
\text { processing }\end{array}$ \\
\hline FSTL3** & Inhibitor of activin $\mathrm{A}$, elevated in $\mathrm{PE}$ and in response to hypoxia \\
\hline$T A P 1 * *$ & Antigen presentation and HLA expression on cell surface \\
\hline
\end{tabular}

Table 5: Genetic biomarkers with the greatest discriminatory potential by qPCR.

*FLT1 and ENG are 2 markers that are highest in PE samples and can differentiate between PE and nonPE samples

**The expression differences between LIMCH1, FSTL3, and TAP1 genes were sufficient for placental cluster assortment by qPCR 
Table 6: Histological differences between 19 Cluster 2 and 5 Cluster 3 PE-IUGR samples.

Cluster 2 PE-IUGR Cluster 3 PE-IUGR

\begin{tabular}{|c|c|c|c|}
\hline Histological attribute & \multicolumn{2}{|c|}{ Percentage of Group } & P-Value \\
\hline Peripheral cord insertion & $2 / 19$ & $1 / 5$ & 0.5212 \\
\hline Velamentous cord insertion & $0 / 19$ & $0 / 5$ & \\
\hline Extrachorialis & $1 / 19$ & $1 / 5$ & 0.3804 \\
\hline 2 vessel cord & $1 / 19$ & $1 / 5$ & 0.3804 \\
\hline Excess cord coiling for GA & $1 / 19$ & $0 / 5$ & 1 \\
\hline True knots & $0 / 19$ & $0 / 5$ & \\
\hline Accessory lobes & $0 / 19$ & $0 / 5$ & \\
\hline Comprehensive retroplacental hematoma & $0 / 19$ & $0 / 5$ & \\
\hline Maternal surface fibrin & $0 / 19$ & $0 / 5$ & \\
\hline Intervillous fibrin & $0 / 19$ & $0 / 5$ & \\
\hline Lesion resemble infarcts & $0 / 19$ & $0 / 5$ & \\
\hline Intervillous thrombi resemble infarcts & $0 / 19$ & $0 / 5$ & \\
\hline Distal villous hypoplasia & $16 / 19$ & $2 / 5$ & 0.07849 \\
\hline Placental infarction* & $13 / 19$ & $0 / 5$ & 0.01087 \\
\hline Advanced villous maturity & $18 / 19$ & $3 / 5$ & 0.09881 \\
\hline Syncytial knots* & $17 / 19$ & $1 / 5$ & 0.006494 \\
\hline Focal perivillous fibrin deposition & $1 / 19$ & $2 / 5$ & 0.09881 \\
\hline Insufficient vessel remodeling & $0 / 5$ & $0 / 2$ & \\
\hline Fibrinoid change & $0 / 5$ & $0 / 2$ & \\
\hline Chorangiosis & $0 / 19$ & $0 / 5$ & \\
\hline Chorangiomas & $0 / 19$ & $0 / 5$ & \\
\hline Local chorangiomatosis & $1 / 19$ & $0 / 5$ & 1 \\
\hline Multifocal chorangiomatosis & $0 / 19$ & $0 / 5$ & \\
\hline Villous immaturity and/or dysmaturity & $3 / 19$ & $3 / 5$ & 0.07849 \\
\hline Avascular fibrotic villi & $0 / 19$ & $0 / 5$ & \\
\hline $\begin{array}{c}\text { Fetal vascular thrombotic lesions and/or } \\
\text { hemorrhage endovasculature }\end{array}$ & $3 / 19$ & $1 / 5$ & 1 \\
\hline Subintimal fibrin cushions & $1 / 18$ & $0 / 5$ & 1 \\
\hline Chorionic hemosiderosis & $0 / 19$ & $0 / 5$ & \\
\hline Retroplacental adhesion blood clots & $2 / 19$ & $1 / 5$ & 0.5212 \\
\hline
\end{tabular}




\begin{tabular}{cccc}
\hline Laminar necrosis of decidua capsularis & $0 / 3$ & $0 / 2$ & 0.004941 \\
Massive perivillous fibrin deposition* & $0 / 19$ & $3 / 5$ & 1 \\
Intervillous thrombi & $4 / 19$ & $1 / 5$ & 0.3804 \\
Idiopathic villitis & $1 / 19$ & $1 / 5$ & 1 \\
Infectious villitis & $0 / 19$ & $0 / 5$ & 0.2083 \\
Chronic deciduitis & $2 / 19$ & $0 / 5$ & 0.3804 \\
Chronic plasma cell deciduitis & $0 / 19$ & $1 / 5$ & $1 / 5$ \\
Intervillous histocytosis & $1 / 19$ & & \\
\hline
\end{tabular}

*Placental infarction, syncytial knots, and massive perivillous fibrin deposition are statistically significant $(\mathrm{p}<0.05)$

\subsubsection{Subclasses of pre-eclampsia}

The molecular and detailed histopathology profiling uses a combination of a qPCR panel and an analysis for the presence of placental lesions that can then be used to identify three different subclasses of PE which exhibit distinct alterations in disease pathways and varying expressions of commonly accepted markers of PE [81]. The clustering technique identified 5 clusters, however only 3 of the clusters (clusters 1, 2, and 3) are related to preeclamptic etiologies: (1) "maternal” PE, (2) “canonical” PE, and (3) "immunologic" PE [82]. This classification of PE has improved our understanding of the diversity of placental pathology that leads to the development PE.

The first subclass of PE consists of maternal CVR factors, such as increased maternal age, elevated BMI, or a history of hypertension, or persistent endothelial damage from a previous pregnancy $[25,84]$ that underlie the development of a later-onset, less severe form of PE, termed "maternal" PE. It does not appear that there is placental dysfunction in this group of women, which indicates that the mother may simply not be adapting to the pregnancy properly, but it does not indicate underlying vascular disease. The second subclass is more severe, early onset [82], and linked to IUGR and HELLP syndrome [87]. Histological examination of PE-IUGR samples from this group revealed signs of distal villous hypoplasia, placental infarction, and syncytial knots (Table 6) [82]. GSEA of this subclass identified placental dysfunction, leading to reduced placental perfusion, hypoxia, and increased production and 
secretion of placental factors (e.g. soluble $F L T 1$ and $E N G$ ) into the maternal blood [82]. This results in the development of "canonical" PE, a pathogenesis arising from a placental origin. The third subclass is also severe and linked to IUGR [82]. This subclass involves an incompatibility between the mother and the fetus [91] which may induce an immune rejection of the placenta, evidenced by elevated levels of CXCL10 [92, 107] a marker of rejected organs. This results in extensive fibrin deposition, secondary placental insufficiency and dysfunction, and fetal growth restriction. The development of "immunologic" PE is likely dependent on the presence of immunologic risk factors, such as an A blood type [92], and the possible absence of immunologic protective factors, such as previous exposure to paternal antigens or a $\mathrm{B}$ blood type [92].

\subsubsection{Discriminatory potential of genetic biomarkers between placental clusters}

Leavey et al. identified a small panel of candidate markers that are able to discriminate between the observed placental clusters [82]. In the future prospective study, we would implement the Leavey et al.'s novel technique of identifying a panel of 11 genes with significant differential expression between the 5 clusters for validation by qPCR [82]. In their study, the preeclamptic samples in cluster 2 expressed the highest levels of FLT1 and ENG and were found to be easily distinguished from all the assessed nonpreeclamptic samples using only these two genes. The remaining 9 genes were assessed for their discriminatory potential between the clusters and resulted in the reduction of the number of markers to distinguish the clusters. These 9 genes included SNX10, MAN1C1, TPBG, TAP1, LIMCH1, FSTL3, MTIF, MORN3, and PIK3CB. However, only 3 of these genes were used in the qPCR panel of candidate markers: LIMCH1, FSTL3, and TAP1 as the genes with the most discriminatory potential between the clusters. These three genes provided enough information to successfully assign the samples to their clusters in the majority (approximately 85\%) of cases [82]. Therefore, we would use a small panel of the 5 candidate markers, including $F L T 1, E N G, L I M C H 1, F S T L 3$, and TAP1 in our qPCR analysis to distinguish between our preeclamptic and non-preeclamptic placenta samples. The expression levels of

these 5 genes are sufficient to successfully assign the samples to the cluster based on their pathology of 
PE, which may identify the women who belong to a cluster that are associated with an increased risk of future CVD.

\subsubsection{Subclasses of pre-eclampsia linked to increased risk of cardiovascular disease}

Leavey et al. have demonstrated a technique to analyze placental tissue with the aim of identifying biochemical, histologic, and clinical markers for PE that may be useful for categorizing the mothers into a subclass of PE. This classification is based on distinct pathophysiology and the influence of maternal factors [82], which may aid in identifying the women at highest risk for CVD. Women who showed very little placental pathology (“maternal” PE) or chronic inflammatory lesions in the placenta (“immunologic PE) demonstrated low CVR profiles at six months postpartum. However, women who present with placental pathologies, specifically lesions of maternal vascular perfusion, are unique to the "canonical" PE subclass. The "canonical" PE subclass consists of women with the most severe form of PE and a co-diagnosis of HELLP syndrome. The woman in this subclass of PE have a high risk for CVD as it is likely poor vascular function that has contributed to the establishment of the disease within the placentas of these women. Therefore, the classification of women into "canonical" PE may aid in identifying the women who should be screened for CVR factors postpartum. 


\section{Chapter 4}

\section{Conclusion}

The implications of PE extend beyond that of the two-stage model (Figure 4). The pathophysiology of PE is multifactorial, yet underlying CVR factors, such as hypertension, elevated BMI, and abnormal lipid profiles, contribute to the development of PE. In a preeclamptic pregnancy, impaired myometrial spiral artery remodeling indicates maladaptive vascularization, creating an increasingly hypoxic utero-placental environment that results in maternal endothelial dysfunction and the presentation of the clinical manifestations of PE, predisposing the mother to future CVD. There are 3 placental etiologies of PE that have been identified: (1) "maternal" PE, (2) "canonical" PE, and (3) "immunologic" PE. The women belonging to the "canonical" PE subclass have the most severe form of PE and a codiagnosis of HELLP syndrome, with placental origin of the disease.

Women who experienced a pregnancy complicated by PE are at an elevated risk for lifetime CVD which may be related to impairments in vascular and metabolic function that extends into and beyond the postpartum period. The placental development during the gestational period sets a trajectory of fetal and perhaps maternal health outcomes following the delivery. In a preeclamptic pregnancy, placental function/dysfunction appears to reflect the underlying maternal environmental background, such as genetics and vascular health, and we speculate that analysis for certain combinations of genes and placental histopathologic lesions, in combination with the PW:BW ratio, may help to determine which women are at greatest risk of future CVD and should undergo postpartum CVR screening. 


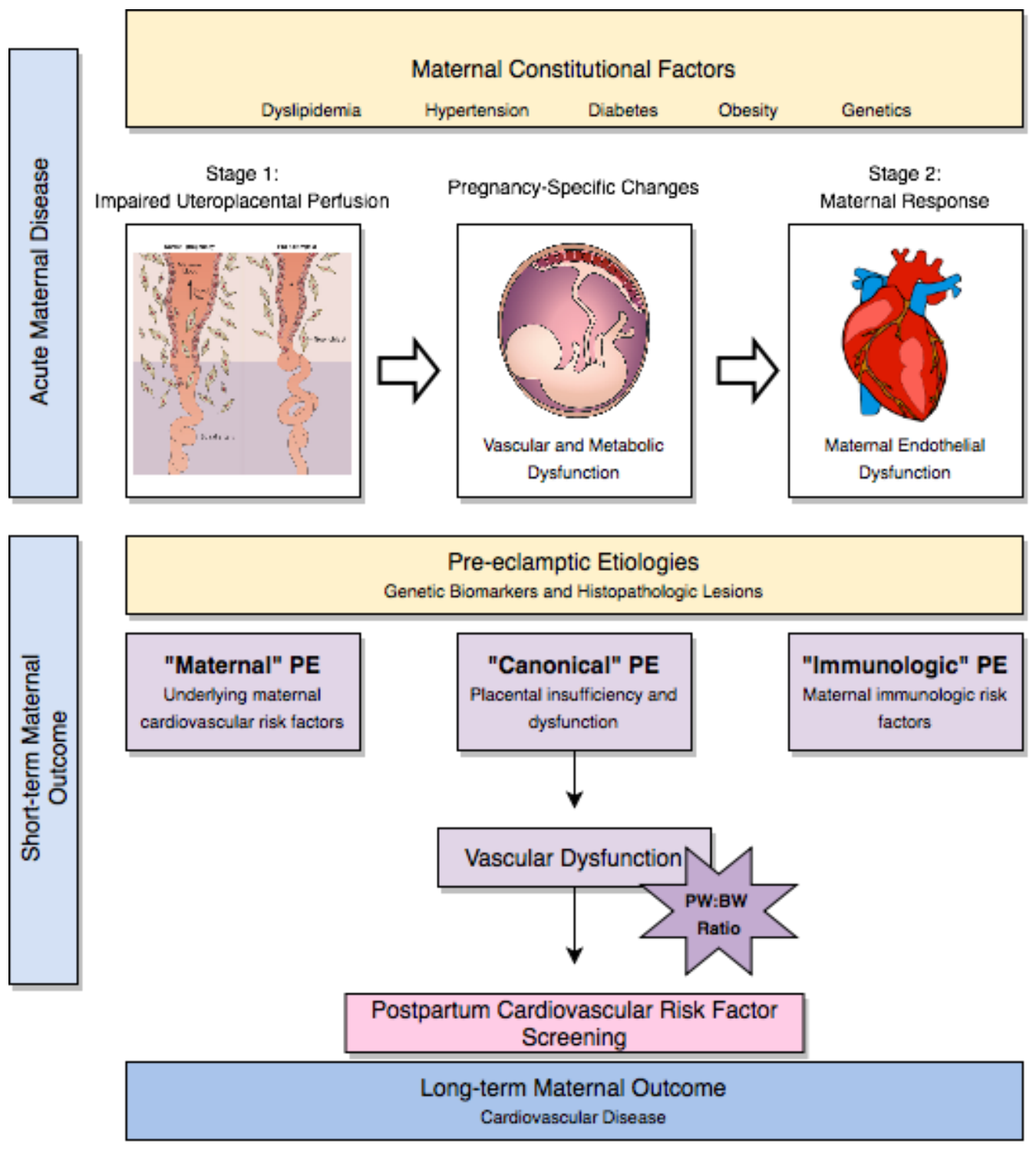

Figure 4: The pathophysiology of pre-eclampsia and the risk of future cardiovascular disease. The implications of pre-eclampsia extend beyond the two-stage model. Placental morphometric measurements in combination with the subclassification of PE may identify who is at greatest risk of future CVD. 


\section{References}

1. R.K. Creasy and Resnik's Maternal-Fetal Medicine: Principles and Practice: Expert Consult Premium Edition. 7th edition. Elsevier Saunders, Philadelphia (2013)

2. Ananth, C., Keyes, K., \& Wapner, R. (2013). Pre-eclampsia rates in the United States, 19802010: age-period-cohort analysis. BMJ : British Medical Journal, 347(nov07 15), f6564-f6564. https://doi.org/10.1136/bmj.f6564

3. Pauli, J., \& Repke, J. (2015). Preeclampsia: Short-term and Long-term Implications. Obstetrics and Gynecology Clinics of North America, 42(2), 299-313.

4. Tranquilli, A., Dekker, G., Magee, L., Roberts, J., Sibai, B., Steyn, W., Zeeman, G., \& Brown, M. (2014). The classification, diagnosis and management of the hypertensive disorders of pregnancy: A revised statement from the ISSHP. Pregnancy Hypertension: An International Journal of Women's Cardiovascular Health, 4(2), 97-104. https://doi.org/10.1016/j.preghy.2014.02.001

5. Sibai, B. (2003). Diagnosis and Management of Gestational Hypertension and Preeclampsia. Obstetrics and Gynecology (New York. 1953), 102(1), 181-192. https://doi.org/10.1016/s0029-7844(03)00475-7

6. Backes, C. H., Markham, K., Moorehead, P., Cordero, L., Nankervis, C. A., \& Giannone, P. J. (2011). Maternal Preeclampsia and Neonatal Outcomes. Journal of Pregnancy, 2011, 1-7. https://doi.org/10.1155/2011/214365

7. Gellersen, B., \& Brosens, J. J. (2014). Cyclic decidualization of the human endometrium in reproductive health and failure. Endocrine reviews, 35(6), 851-905.

8. Redman, C. (2005). Latest Advances in Understanding Preeclampsia. Science (American Association for the Advancement of Science), 308(5728), 1592-1594. https://doi.org/10.1126/science.1111726

9. Zhang, J., Adams, M. A., \& Croy, B. A. (2011). Alterations in maternal and fetal heart functions accompany failed spiral arterial remodeling in pregnant mice. American Journal of Obstetrics and Gynecology, 205(5), 485.e1-485.e16. https://doi.org/10.1016/j.ajog.2011.06.008

10. Smith, S. D., Dunk, C. E., Aplin, J. D., Harris, L. K., \& Jones, R. L. (2009). Evidence for immune cell involvement in decidual spiral arteriole remodeling in early human pregnancy. American Journal of Pathology, 174(5), 1959-1971. https://doi.org/10.2353/ajpath.2009.080995

11. Fisher, S. J. (1999). Defects in placentation and placental perfusion. Chelsey's hypertensive disorders in pregnancy, 377-394.

12. Brosens, I. A. (1988). The Utero-Placental Vessels at Term - the Distribution and Extent of Physiological Changes. In Placental Vascularization and Blood Flow. https://doi.org/10.1007/978-1-4615-8109-3_5

13. Brosens, J. J., Pijnenborg, R., \& Brosens, I. A. (2002). The myometrial junctional zone spiral arteries in normal and abnormal pregnancies: a review of the literature. American Journal of Obstetrics and Gynecology, 187(5), 1416-1423. 
14. Cotechini, T., Komisarenko, M., Sperou, A., Macdonald-Goodfellow, S., Adams, M. A., \& Graham, C. H. (2014). Inflammation in rat pregnancy inhibits spiral artery remodeling leading to fetal growth restriction and features of preeclampsia. The Journal of Experimental Medicine, 211(1), 165-179. https://doi.org/10.1084/jem.20130295

15. Ahmed, R., Dunford, J., Mehran, R., Robson, S., \& Kunadian, V. (2014). Pre-eclampsia and future cardiovascular risk among women: a review. Journal of the American College of Cardiology, 63(18), 1815-1822.

16. Steegers, E. A., Von Dadelszen, P., Duvekot, J. J., \& Pijnenborg, R. (2010). Preeclampsia. The Lancet, 376(9741), 631-644

17. Levine, R., Maynard, S., Qian, C., Lim, K., England, L., Yu, K., Schisterman, E., Thadhani, R., Sachs, B., Epstein, F., Sibai, B., Sukhatme, V., \& Karumanchi, S. (2004). Circulating Angiogenic Factors and the Risk of Preeclampsia. The New England Journal of Medicine, 350(7), 672-683. https://doi.org/10.1056/nejmoa031884

18. Maynard, S., Min, J., Merchan, J., Lim, K., Li, J., Mondal, S., Libermann, T., Morgan, J., Sellke, F., Stillman, I., Epstein, F., Sukhatme, V., \& Karumanchi, S. (2003). Excess placental soluble fms-like tyrosine kinase 1 (sFlt1) may contribute to endothelial dysfunction, hypertension, and proteinuria in preeclampsia. The Journal of Clinical Investigation, 111(5), 649-658. https://doi.org/10.1172/JCI200317189

19. Zhou, Y., McMaster, M., Woo, K., Janatpour, M., Perry, J., Karpanen, T., Alitalo, K., Damsky, C., \& Fisher, S. J. (2002). Vascular endothelial growth factor ligands and receptors that regulate human cytotrophoblast survival are dysregulated in severe preeclampsia and hemolysis, elevated liver enzymes, and low platelets syndrome. The American journal of pathology, 160(4), 14051423. https://doi.org/10.1016/S0002-9440(10)62567-9

20. Gilbert, J., Ryan, M., LaMarca, B., Sedeek, M., Murphy, S., \& Granger, J. (2008). Pathophysiology of hypertension during preeclampsia: linking placental ischemia with endothelial dysfunction. American Journal of Physiology. Heart and Circulatory Physiology, 294(2), H541-H550. https://doi.org/10.1152/ajpheart.01113.2007

21. Granger, J. P., Alexander, B. T., Llinas, M. T., Bennett, W. A., \& Khalil, R. A. (2001). Pathophysiology of hypertension during preeclampsia linking placental ischemia with endothelial dysfunction. Hypertension, 38(3), 718-722

22. Roberts, J. M., Taylor, R. N., Musci, T. J., Rodgers, G. M., Hubel, C. A., \& McLaughlin, M. K. (1990). Preeclampsia: An endothelial cell disorder. International Journal of Gynecology \& Obstetrics, 32(3), 299-299.

23. Roberts, J., \& Cooper, D. (2001). Pathogenesis and genetics of pre-eclampsia. The Lancet (British Edition), 357(9249), 53-56. https://doi.org/10.1016/s0140-6736(00)03577-7

24. Brown, M., Lindheimer, M., Swiet, M., Assche, A., \& Moutquin, J. (2001). The Classification and Diagnosis of the Hypertensive Disorders of Pregnancies: Statement from the International 
Society for the Study of Hypertension in Pregnancy (ISSHP). Hypertension in Pregnancy, 20(1), ix-xiv. https://doi.org/10.1081/prg-100104165

25. Chambers, J., Fusi, L., Malik, I., Haskard, D., De Swiet, M., \& Kooner, J. (2001). Association of Maternal Endothelial Dysfunction With Preeclampsia. Obstetrical \& Gynecological Survey, 56(10), 596-597. https://doi.org/10.1097/00006254-200110000-00002

26. Pohl, U., Holtz, J., Busse, R., \& Bassenge, E. (1986). Crucial Role of Endothelium in the Vasodilator Response to Increased Flow in Vivo. Hypertension (Dallas, Tex. 1979), 8(1), 37-44. https://doi.org/10.1161/01.HYP.8.1.37

27. Cai, H., \& Harrison, D. G. (2000). Endothelial dysfunction in cardiovascular diseases: The role of oxidant stress. Circulation Research. https://doi.org/10.1161/01.RES.87.10.840

28. Bellamy, L., Casas, J., Hingorani, A., \& Williams, D. (2007). Pre-eclampsia and risk of cardiovascular disease and cancer in later life: systematic review and metaanalysis. BMJ, 335(7627), 974-977. https://doi.org/10.1136/bmj.39335.385301.BE

29. Rajendran, P., Rengarajan, T., Thangavel, J., Nishigaki, Y., Sakthisekaran, D., Sethi, G., \& Nishigaki, I. (2013). The vascular endothelium and human diseases. International Journal of Biological Sciences. https://doi.org/10.7150/ijbs.7502

30. Smith, G., Walker, M., Liu, A., Wen, S., Swansburg, M., Ramshaw, H., White, R., Roddy, M., \& Hladunewich, M. (2009). A history of preeclampsia identifies women who have underlying cardiovascular risk factors. American Journal of Obstetrics and Gynecology, 200(1), 58.e1-58.e8. https://doi.org/10.1016/j.ajog.2008.06.035

31. Smith, G., Pell, J., \& Walsh, D. (2001). Pregnancy complications and maternal risk of ischaemic heart disease: a retrospective cohort study of 129a290 births. The Lancet, 357(9273). https://doi.org/10.1016/S0140-6736(00)05112-6

32. Ray, J., Vermeulen, M., Schull, M., \& Redelmeier, D. (2005). Cardiovascular health after maternal placental syndromes (CHAMPS): population-based retrospective cohort study. The Lancet (British Edition), 366(9499), 1797-1803. https://doi.org/10.1016/s0140-6736(05)67726-4

33. Funai, E., Paltiel, O., Malaspina, D., Friedlander, Y., Deutsch, L., \& Harlap, S. (2005). Risk factors for pre-eclampsia in nulliparous and parous women: the Jerusalem Perinatal Study. Paediatric and Perinatal Epidemiology, 19(1), 59-68. https://doi.org/10.1111/j.13653016.2004.00623.x

34. Sabour, S., Franx, A., Rutten, A., Grobbee, D., Prokop, M., Bartelink, M., van der Schouw, Y., \& Bots, M. (2007). High Blood Pressure in Pregnancy and Coronary Calcification. Hypertension (Dallas, Tex. 1979), 49(4), 813-817. https://doi.org/10.1161/01.HYP.0000258595.09320.eb

35. Zeek, P., \& Assali, N. (1951). Vascular changes in the decidua associated with eclamptogenic toxemia of pregnancy. Obstetrical \& Gynecological Survey, 6(2), 187-191. https://doi.org/10.1097/00006254-195104000-00019

36. Ray, J. (2004). Dysmetabolic syndrome, placenta-mediated disease and future risk of cardiovascular disease. Fetal and Maternal Medicine Review, 15(3), 231-246. https://doi.org/10.1017/S0965539504001287 
37. Cetin, I., Foidart, J., Miozzo, M., Raun, T., Jansson, T., Tsatsaris, V., Reik, W., Cross, J., Hauguel-de-Mouzon, S., Illsley, N., Kingdom, J., \& Huppertz, B. (2004). Fetal growth restriction: a workshop report. Placenta, 25(8), 753-757. https://doi.org/10.1016/j.placenta.2004.02.004

38. Manten, G., Sikkema, M., Voorbij, H., Visser, G., Bruinse, H., \& Franx, A. (2007). Risk Factors for Cardiovascular Disease in Women with a History of Pregnancy Complicated by Preeclampsia or Intrauterine Growth Restriction. Hypertension in Pregnancy, 26(1), 39-50. https://doi.org/10.1080/10641950601146574

39. Forest, J., Girouard, J., Massé, J., Moutquin, J., Kharfi, A., Ness, R., Roberts, J., \& Giguère, Y. (2005). Early occurrence of metabolic syndrome after hypertension in pregnancy. Obstetrics and Gynecology (New York. 1953), 105(6), 1373-1380.

https://doi.org/10.1097/01.AOG.0000163252.02227.f8

40. Bar, J., Kaplan, B., Wittenberg, C., Erman, A., Boner, G., Ben-Rafael, Z., \& Hod, M. (1999). Microalbuminuria after pregnancy complicated by pre-eclampsia. Nephrology, Dialysis, Transplantation, 14(5), 1129-1132. https://doi.org/10.1093/ndt/14.5.1129

41. North, R., Simmons, D., Bamfather, D., \& Upjohn, M. (1996). What Happens to Women with Preeclampsia? Microalbuminuria and Hypertension Following Preeclampsia. Australian and New Zealand Journal of Obstetrics and Gynaecology, 36(3), 233-238. https://doi.org/10.1111/j.1479828X.1996.tb02702.x

42. Agrawal, B., Berger, A., Wolf, K., \& Luft, F. (1996). Microalbuminuria screening by reagent strip predicts cardiovascular risk in hypertension. Journal of Hypertension, 14(2), 223-228. https://doi.org/10.1097/00004872-199602000-00011

43. Bianchi, S., Bigazzi, R., \& Campese, V. M. (1999). Microalbuminuria in essential hypertension: significance, pathophysiology, and therapeutic implications. American journal of kidney diseases, 34(6), 973-995.

44. Deckert, T., Feldt-Rasmussen, B., Borch-Johnsen, K., Jensen, T., \& Kofoed-Enevoldsen, A. (1989). Albuminuria reflects widespread vascular damage: The Steno hypothesis. Diabetologia, 32(4), 219-226. https://doi.org/10.1007/BF00285287

45. Garovic, V., Bailey, K., Boerwinkle, E., Hunt, S., Weder, A., Curb, D., Mosley, T., Wiste, H., \& Turner, S. (2010). Hypertension in pregnancy as a risk factor for cardiovascular disease later in life. Journal of Hypertension, 28(4), 826-833. https://doi.org/10.1097/hjh.0b013e328335c29a

46. Sattar, N., \& Greer, I. (2002). Pregnancy complications and maternal cardiovascular risk: opportunities for intervention and screening? BMJ, 325(7356), 157-160. https://doi.org/10.1136/bmj.325.7356.157

47. Greer, I. (1999). Thrombosis in pregnancy: maternal and fetal issues. The Lancet (British Edition), 353(9160), 1258-1265. https://doi.org/10.1016/s0140-6736(98)10265-9

48. Martin, U., Davies, C., Hayavi, S., Hartland, A., \& Dunne, F. (1999). Is normal pregnancy atherogenic? Clinical Science (1979), 96(4), 421-. https://doi.org/10.1042/CS19980326 
49. Sacks, G., Studena, K., Sargent, I., \& Redman, C. (1998). Normal pregnancy and preeclampsia both produce inflammatory changes in peripheral blood leukocytes akin to those of sepsis. American Journal of Obstetrics and Gynecology, 179(1), 80-86. https://doi.org/10.1016/s0002-9378(98)70254-6

50. Sattar, N., Gaw, A., Packard, C., \& Greer, I. (1996). Potential pathogenic roles of aberrant lipoprotein and fatty acid metabolism in pre-eclampsia. BJOG: An International Journal of Obstetrics \& Gynaecology, 103(7), 614-620. https://doi.org/10.1111/j.1471-0528.1996.tb09827.x

51. Stekkinger, E., Zandstra, M., Peeters, L., \& Spaanderman, M. (2009). Early-Onset Preeclampsia and the Prevalence of Postpartum Metabolic Syndrome. Obstetrics and Gynecology (New York. 1953), 114(5), 1076-1084. https://doi.org/10.1097/aog.0b013e3181b7b242

52. Sattar, N., Ramsay, J., Crawford, L., Cheyne, H., \& Greer, I. (2003). Classic and Novel Risk Factor Parameters in Women With a History of Preeclampsia. Hypertension (Dallas, Tex. 1979), 42(1), 39-42. https://doi.org/10.1161/01.HYP.0000074428.11168.EE

53. Raijmakers, M., Roes, E., Zusterzeel, P., Steegers, E., \& Peters, W. (2004). Thiol status and antioxidant capacity in women with a history of severe pre-eclampsia. BJOG: An International Journal of Obstetrics and Gynaecology, 111(3), 207-212. https://doi.org/10.1111/j.14710528.2004.00051.x

54. Rodie, V. (2004). Pre-eclampsia and cardiovascular disease: metabolic syndrome of pregnancy? Atherosclerosis, 175(2), 189-202. https://doi.org/10.1016/j.atherosclerosis.2004.01.038

55. Agatisa, P., Ness, R., Roberts, J., Costantino, J., Kuller, L., \& McLaughlin, M. (2004). Impairment of endothelial function in women with a history of preeclampsia: an indicator of cardiovascular risk. American Journal of Physiology. Heart and Circulatory Physiology, 286(4), H1389-H1393. https://doi.org/10.1152/ajpheart.00298.2003

56. Smith, G. N., Pudwell, J., Walker, M., \& Wen, S. W. (2012). Risk estimation of metabolic syndrome at one and three years after a pregnancy complicated by preeclampsia. Journal of Obstetrics and Gynaecology Canada, 34(9), 836-841.

57. Barden, A., Beilin, L., Ritchie, J., Walters, B., \& Michael, C. (1999). Does a predisposition to the metabolic syndrome sensitize women to develop pre-eclampsia? Journal of Hypertension, 17(9), 1307-1315. https://doi.org/10.1097/00004872-199917090-00011

58. Williams, D. (2003). Pregnancy: a stress test for life. Current Opinion in Obstetrics \& Gynecology, 15(6), 465-471. https://doi.org/10.1097/00001703-200312000-00002

59. Rich-Edwards, J., McElrath, T., Karumanchi, S., \& Seely, E. (2010). Breathing Life Into the Lifecourse Approach: Pregnancy History and Cardiovascular Disease in Women. Hypertension (Dallas, Tex. 1979), 56(3), 331-334. https://doi.org/10.1161/HYPERTENSIONAHA.110.156810

60. Thornburg, K., Kolahi, K., Pierce, M., Valent, A., Drake, R., \& Louey, S. (2016). Biological features of placental programming. Placenta, 48(Suppl 1), S47-S53.

https://doi.org/10.1016/j.placenta.2016.10.012 
61. Barker, D., Osmond, C., Thornburg, K., Kajantie, E., \& Eriksson, J. (2013). The shape of the placental surface at birth and colorectal cancer in later life. American Journal of Human Biology, 25(4), 566-568. https://doi.org/10.1002/ajhb.22409

62. Eriksson, J., Kajantie, E., Thornburg, K., Osmond, C., \& Barker, D. (2011). Mother's body size and placental size predict coronary heart disease in men. European Heart Journal, 32(18), 2297 2303. https://doi.org/10.1093/eurheartj/ehr147

63. Barker, D., Osmond, C., Thornburg, K., Kajantie, E., \& Eriksson, J. (2011). The lifespan of men and the shape of their placental surface at birth. Placenta, 32(10), 783-787.

https://doi.org/10.1016/j.placenta.2011.07.031

64. Martyn, C., Barker, D., \& Osmond, C. (1996). Mothers' pelvic size, fetal growth, and death from stroke and coronary heart disease in men in the UK. The Lancet (British Edition), 348(9037), 1264-1268. https://doi.org/10.1016/s0140-6736(96)04257-2

65. Wilson, M. E., \& Ford, S. P. (2001). Comparative aspects of placental efficiency. Reproduction (Cambridge, England) Supplement, 58, 223.

66. Barker, D., Osmond, C., Forsén, T., Kajantie, E., \& Eriksson, J. (2005). Trajectories of Growth among Children Who Have Coronary Events as Adults. The New England Journal of Medicine, 353(17), 1802-1809. https://doi.org/10.1056/nejmoa044160

67. Eriksson, J., Forsén, T., Tuomilehto, J., Osmond, C., \& Barker, D. (2000). Fetal and Childhood Growth and Hypertension in Adult Life. Hypertension (Dallas, Tex. 1979), 36(5), 790-794. https://doi.org/10.1161/01.hyp.36.5.790

68. Barker, D., \& Thornburg, K. (2013). Placental programming of chronic diseases, cancer and lifespan: A review. Placenta, 34(10), 841-845. https://doi.org/10.1016/j.placenta.2013.07.063

69. Burton, G. J., Barker, D. J., Moffett, A., \& Thornburg, K. (Eds.). (2010). The placenta and human developmental programming. Cambridge University Press.

70. Thornburg, K., \& Marshall, N. (2015). The placenta is the center of the chronic disease universe. American Journal of Obstetrics and Gynecology, 213(4), S14-S20.

https://doi.org/10.1016/j.ajog.2015.08.030

71. Alwasel, S., Abotalib, Z., Aljarallah, J., Osmond, C., Al Omar, S., Harrath, A., Thornburg, K., \& Barker, D. (2012). The breadth of the placental surface but not the length is associated with body size at birth. Placenta, 33(8), 619-622. https://doi.org/10.1016/j.placenta.2012.04.015

72. Barker, D., Osmond, C., Thornburg, K., Kajantie, E., \& Eriksson, J. (2011). The lifespan of men and the shape of their placental surface at birth. Placenta, 32(10), 783-787. https://doi.org/10.1016/j.placenta.2011.07.031

73. Barker, D., Gelow, J., Thornburg, K., Osmond, C., Kajantie, E., \& Eriksson, J. (2010). The early origins of chronic heart failure: impaired placental growth and initiation of insulin resistance in childhood. European Journal of Heart Failure, 12(8), 819-825.

https://doi.org/10.1093/eurjhf/hfq069 
74. Barker, D. J., Thornburg, K. L., Osmond, C., Kajantie, E., \& Eriksson, J. G. (2010). The surface area of the placenta and hypertension in the offspring in later life. The International journal of developmental biology, 54, 525 .

75. Barker, D., Thornburg, K., Osmond, C., Kajantie, E., \& Eriksson, J. (2010). The prenatal origins of lung cancer. II. The placenta. American Journal of Human Biology, 22(4), 512-516. https://doi.org/10.1002/ajhb.21041

76. Kajantie, E., Thornburg, K., Eriksson, J. G., Osmond, L., \& Barker, D. J. (2009). In preeclampsia, the placenta grows slowly along its minor axis. International Journal of Developmental Biology, 54(2-3), 469-473.

77. Barker, D., Osmond, C., Forsén, T., Thornburg, K., Kajantie, E., \& Eriksson, J. (2013). Foetal and childhood growth and asthma in adult life. Acta Pædiatrica (Oslo), 102(7), 732-738. https://doi.org/10.1111/apa.12257

78. Barker, D., Osmond, C., Thornburg, K., Kajantie, E., \& Eriksson, J. (2013). The intrauterine origins of Hodgkin's lymphoma. Cancer Epidemiology, 37(3), 321-323. https://doi.org/10.1016/j.canep.2013.01.004

79. Tuovinen, S., Räikkönen, K., Kajantie, E., Pesonen, A. K., Heinonen, K., Osmond, C., ... Eriksson, J. G. (2010). Depressive symptoms in adulthood and intrauterine exposure to preeclampsia: The Helsinki birth cohort study. BJOG: An International Journal of Obstetrics and Gynaecology. https://doi.org/10.1111/j.1471-0528.2010.02634.x

80. Burton, G. J., \& Jauniaux, E. (2011). The maternal circulation and placental shape. In The placenta and human developmental programming (pp. 161-171). Cambridge University Press, Cambridge.

81. Leavey, K., Bainbridge, S., \& Cox, B. (2015). Large Scale Aggregate Microarray Analysis Reveals Three Distinct Molecular Subclasses of Human Preeclampsia. PloS One, 10(2), e0116508-. https://doi.org/10.1371/journal.pone.0116508

82. Leavey, K., Benton, S., Grynspan, D., Kingdom, J., Bainbridge, S., \& Cox, B. (2016). Unsupervised Placental Gene Expression Profiling Identifies Clinically Relevant Subclasses of Human Preeclampsia. Hypertension (Dallas, Tex. 1979), 68(1), 137-147. https://doi.org/10.1161/hypertensionaha.116.07293

83. Ødegård, R., Vatten, L., Nilsen, S., Salvesen, K., \& Austgulen, R. (2000). Risk factors and clinical manifestations of pre-eclampsia. BJOG: An International Journal of Obstetrics \& Gynaecology, 107(11), 1410-1416. https://doi.org/10.1111/j.1471-0528.2000.tb11657.x

84. Romundstad, P., Magnussen, E., Smith, G., \& Vatten, L. (2010). Hypertension in pregnancy and later cardiovascular risk: common antecedents? Circulation (New York, N.Y.), 122(6), 579-584. https://doi.org/10.1161/CIRCULATIONAHA.110.943407

85. Nishizawa, H., Pryor-Koishi, K., Kato, T., Kowa, H., Kurahashi, H., \& Udagawa, Y. (2007). Microarray Analysis of Differentially Expressed Fetal Genes in Placental Tissue Derived from Early and Late Onset Severe Pre-eclampsia. Placenta, 28(5), 487-497. https://doi.org/10.1016/j.placenta.2006.05.010 
86. Sitras, V., Paulssen, R., Grønaas, H., Leirvik, J., Hanssen, T., Vårtun, Å., \& Acharya, G. (2009). Differential Placental Gene Expression in Severe Preeclampsia. Placenta, 30(5), 424-433. https://doi.org/10.1016/j.placenta.2009.01.012

87. Várkonyi, T., Nagy, B., Füle, T., Tarca, A., Karászi, K., Schönléber, J., Hupuczi, P., Mihalik, N., Kovalszky, I., Rigó, J., Meiri, H., Papp, Z., Romero, R., \& Than, N. (2011). Microarray Profiling Reveals That Placental Transcriptomes of Early-onset HELLP Syndrome and Preeclampsia Are Similar. Placenta, 32, S21-S29. https://doi.org/10.1016/j.placenta.2010.04.014

88. Vaiman, D., Calicchio, R., \& Miralles, F. (2013). Landscape of Transcriptional Deregulations in the Preeclamptic Placenta. PloS One, 8(6), e65498. https://doi.org/10.1371/journal.pone.0065498

89. Akhlaq, M., Nagi, A., \& Yousaf, A. (2012). Placental morphology in pre-eclampsia and eclampsia and the likely role of NK cells. Indian Journal of Pathology \& Microbiology, 55(1), 17-21. https://doi.org/10.4103/0377-4929.94848.

90. Stark, M., Clark, L., \& Craver, R. (2014). Histologic Differences in Placentas of Preeclamptic/Eclamptic Gestations by Birthweight, Placental Weight, and Time of Onset. Pediatric and Developmental Pathology, 17(3), 181-189. https://doi.org/10.2350/13-091378-OA.1

91. Romero, R., Whitten, A., Korzeniewski, S., Than, N., Chaemsaithong, P., Miranda, J., Dong, Z., Hassan, S., \& Chaiworapongsa, T. (2013). Maternal Floor Infarction/Massive Perivillous Fibrin Deposition: A Manifestation of Maternal Antifetal Rejection? American Journal of Reproductive Immunology (1989), 70(4), 285-298. https://doi.org/10.1111/aji.12143

92. Phaloprakarn, C., \& Tangjitgamol, S. (2013). Maternal ABO blood group and adverse pregnancy outcomes. Journal of Perinatology, 33(2), 107-111. https://doi.org/10.1038/jp.2012.73

93. Alsnes, I., Janszky, I., Forman, M., Vatten, L., \& Økland, I. (2014). A population-based study of associations between preeclampsia and later cardiovascular risk factors. American Journal of Obstetrics and Gynecology, 211(6), 657.e1-657.e7. https://doi.org/10.1016/j.ajog.2014.06.026

94. Craici, I., Wagner, S., \& Garovic, V. (2008). Preeclampsia and future cardiovascular risk: formal risk factor or failed stress test? Therapeutic Advances in Cardiovascular Disease, 2(4), 249-259. https://doi.org/10.1177/1753944708094227

95. Hladunewich, M., Karumanchi, S., \& Lafayette, R. (2007). Pathophysiology of the Clinical Manifestations of Preeclampsia. Clinical Journal of the American Society of Nephrology, 2(3), 543-549. https://doi.org/10.2215/cjn.03761106

96. Cusimano, M., Pudwell, J., Roddy, M., Cho, C., \& Smith, G. (2014). The maternal health clinic: an initiative for cardiovascular risk identification in women with pregnancy-related complications. American Journal of Obstetrics and Gynecology, 210(5), 438.e1-438.e9. https://doi.org/10.1016/j.ajog.2013.12.001

97. Smith, G. (2015). The Maternal Health Clinic: Improving women's cardiovascular health. Seminars in Perinatology, 39(4), 316-319. https://doi.org/10.1053/j.semperi.2015.05.012 
98. Ingelsson, E., Sullivan, L., Murabito, J., Fox, C., Benjamin, E., Polak, J., Meigs, J., Keyes, M., O'Donnell, C., Wang, T., D'Agostino, R., Wolf, P., \& Vasan, R. (2007). Prevalence and Prognostic Impact of Subclinical Cardiovascular Disease in Individuals With the Metabolic Syndrome and Diabetes. Diabetes (New York, N.Y.), 56(6), 1718-1726. https://doi.org/10.2337/db07-0078

99. Roberts, J., \& Gammill, H. (2006). Insulin Resistance in Preeclampsia. Hypertension (Dallas, Tex. 1979), 47(3), 341-342. https://doi.org/10.1161/01.hyp.0000205123.40068.84

100. Godfrey, K. (2002). The Role of the Placenta in Fetal Programming-A Review. Placenta, 23, S20-S27. https://doi.org/10.1053/plac.2002.0773

101. Hypertension in pregnancy. Report of the American College of Obstetricians and Gynecologists' Task Force on Hypertension in Pregnancy. (2013). Obstetrics and Gynecology (New York. 1953), 122(5), 1122.

102. Audibert, F., Friedman, S., Frangieh, A., \& Sibai, B. (1996). Clinical utility of strict diagnostic criteria for the HELLP (hemolysis, elevated liver enzymes, and low platelets) syndrome. American Journal of Obstetrics and Gynecology, 175(2), 460-464. https://doi.org/10.1016/s0002-9378(96)70162-x

103. Kramer, M., Platt, R., Wen, S., Joseph, K., Allen, A., Abrahamowicz, M., Blondel, B., \& Breart, G. (2001). A New and Improved Population-Based Canadian Reference for Birth Weight for Gestational Age. Pediatrics (Evanston), 108(2), e35-e35. https://doi.org/10.1542/peds.108.2.e35

104. Cole, T., \& Green, P. (1992). Smoothing reference centile curves: The lms method and penalized likelihood. Statistics in Medicine, 11(10), 1305-1319.

https://doi.org/10.1002/sim.4780111005

105. Shehata, F., Levin, I., Shrim, A., Ata, B., Weisz, B., Gamzu, R., \& Almog, B. (2011). Placenta/birthweight ratio and perinatal outcome: a retrospective cohort analysis. BJOG : an International Journal of Obstetrics and Gynaecology, 118(6), 741-747. https://doi.org/10.1111/j.1471-0528.2011.02892.x

106. Lloyd-Jones, D., Leip, E., Larson, M., D’Agostino, R., Beiser, A., Wilson, P., Wolf, P., \& Levy, D. (2006). Prediction of Lifetime Risk for Cardiovascular Disease by Risk Factor Burden at 50 Years of Age. Circulation (New York, N.Y.), 113(6), 791-798. https://doi.org/10.1161/circulationaha.105.548206

107. Agostini, C., Calabrese, F., Rea, F., Facco, M., Tosoni, A., Loy, M., Binotto, G., Trentin, L., \& Semenzato, G. (2001). Cxcr3 and its ligand CXCL10 are expressed by inflammatory cells infiltrating lung allografts and mediate chemotaxis of $\mathrm{T}$ cells at sites of rejection. The American journal of pathology, 158(5), 1703-1711. 


\section{Appendix A}

\section{Supplementary Tables}

Table 7: Maternal clinical characteristics and their lifetime cardiovascular disease risk profiles and metabolic syndrome risk profiles calculated at 6 months postpartum. Data presented as mean (SD) if normally distributed data, as median [IQR] if not normally distributed data, and as number $(\%)$ if categorical.

\begin{tabular}{|c|c|c|c|c|c|c|c|}
\hline & All Participants & & By CVD Risk Category & & By & abolic Syndrome C & \\
\hline & $\mathrm{N}=186$ & High Risk & Low Risk & P-Value & Yes & No & P-Value \\
\hline & & $\mathrm{N}=85$ & $\mathrm{~N}=76$ & & $\mathrm{~N}=32$ & $\mathrm{~N}=129$ & \\
\hline Maternal Age (years) & & & & & & & \\
\hline Mean (SD) & $31.4(5.5)$ & $32.1(5.5)$ & $30.9(5.4)$ & 0.19 & $32.3(6.5)$ & $31.3(5.2)$ & 0.40 \\
\hline BMI $\left(\mathrm{kg} / \mathrm{m}^{2}\right)$ & & & & & & & \\
\hline Median [IQR] & $26.2[22.4-31.5]$ & $27.7[23.4-32.0]$ & $24.7[21.2-28.6]$ & $0.008 *$ & $33.9[28.5-39.3]$ & $24.6[21.8-28.4]$ & $<0.001 *$ \\
\hline Unknown & 1 & 0 & 1 & & & & \\
\hline Race, n (\%) & & & & & & & \\
\hline Caucasian & $166(91.2)$ & 77 (91.7) & $66(89.2)$ & 0.61 & $30(93.8)$ & $113(89.7)$ & 0.76 \\
\hline Other & $16(8.8)$ & $7(8.3)$ & $8(10.8)$ & & $2(6.2)$ & $13(110.3)$ & \\
\hline Unknown & 4 & 1 & 2 & & 0 & 3 & \\
\hline Education, n (\%) & & & & & & & \\
\hline University or College Complete & $152(92.6)$ & $70(83.3)$ & $67(89.3)$ & 0.28 & $29(90.6)$ & $108(85.0)$ & 0.69 \\
\hline Some University or College & $13(7.1)$ & $5(6.0)$ & $5(6.7)$ & & $2(6.3)$ & $8(6.3)$ & \\
\hline High School or Less & $19(10.3)$ & $9(10.7)$ & $3(4.0)$ & & $1(3.1)$ & $11(8.7)$ & \\
\hline Unknown & 2 & 1 & 1 & & 0 & 2 & \\
\hline Income, n (\%) & & & & & & & \\
\hline$\geq \$ 90,000$ & $78(45.3)$ & $34(44.2)$ & $37(51.4)$ & 0.46 & $11(35.5)$ & $60(50.8)$ & 0.12 \\
\hline$\$ 60-89,000$ & $48(27.9)$ & $20(26.0)$ & $21(29.2)$ & & $8(25.8)$ & $33(28.0)$ & \\
\hline$\$ 30-59,000$ & $30(17.4)$ & $14(18.2)$ & $10(13.9)$ & & $7(22.6)$ & $17(14.4)$ & \\
\hline$<\$ 30,000$ & $16(9.3)$ & $9(11.7)$ & $4(5.6)$ & & $5(16.1)$ & $8(6.8)$ & \\
\hline
\end{tabular}




\begin{tabular}{|c|c|c|c|c|c|c|c|}
\hline Unknown & 14 & 8 & 4 & & 1 & 11 & \\
\hline \multicolumn{8}{|l|}{ Smoking, n (\%) } \\
\hline Yes & $15(8.1)$ & $11(12.9)$ & 0 & $0.001 *$ & $4(12.5)$ & $7(5.4)$ & 0.30 \\
\hline No & $171(91.9)$ & $74(87.1)$ & $76(100.0)$ & & $28(87.5)$ & $122(94.6)$ & \\
\hline \multicolumn{8}{|l|}{ Lifetime CVD Risk, n (\%) } \\
\hline All Optimal & $31(19.3)$ & 0 & $31(40.8)$ & $<0.001 *$ & 0 & $31(24.0)$ & $<0.001 *$ \\
\hline One or More Not Optimal & $45(28.0)$ & 0 & $45(59.2)$ & & $5(15.6)$ & $40(31.0)$ & \\
\hline One or More Elevated & $47(29.2)$ & $47(55.3)$ & 0 & & $12(37.5)$ & $35(27.1)$ & \\
\hline 1 Major & $24(14.9)$ & $24(28.2)$ & 0 & & $8(25.0)$ & $16(12.4)$ & \\
\hline 2 or More Major & $14(8.7)$ & $14(16.5)$ & 0 & & $7(21.9)$ & $7(5.4)$ & \\
\hline Unknown & 25 & 0 & 0 & & 0 & 0 & \\
\hline \multicolumn{8}{|l|}{ Metabolic Syndrome, n (\%) } \\
\hline Yes & $32(19.9)$ & $27(31.8)$ & $5(6.6)$ & $<0.001 *$ & $32(100.0)$ & 0 & $<0.001 *$ \\
\hline No & $129(80.1)$ & $58(68.2)$ & $71(93.4)$ & & 0 & $129(100.0)$ & \\
\hline Unknown & 25 & 0 & 0 & & 0 & 0 & \\
\hline
\end{tabular}


Table 8: Placental measurements according to lifetime cardiovascular disease risk profiles and metabolic syndrome risk profiles calculated at 6 months postpartum. Data presented as mean (SD) if normally distributed data and as number (\%) if categorical.

By CVD Risk Category

By Metabolic Syndrome Category

\begin{tabular}{|c|c|c|c|c|c|c|}
\hline & High Risk & Low Risk & P-Value & Yes & No & P-Value \\
\hline & $\mathrm{N}=85$ & $\mathrm{~N}=76$ & & $\mathrm{~N}=32$ & $\mathrm{~N}=129$ & \\
\hline \multicolumn{7}{|l|}{ Placental Weight (grams) } \\
\hline Mean (SD) & $477.1(182.7)$ & $511.9(193.7)$ & 0.25 & $503.7(169.9)$ & $491.0(192.9)$ & 0.74 \\
\hline Unknown & 1 & 1 & & 1 & 1 & \\
\hline \multicolumn{7}{|l|}{ Neonatal Weight (grams) } \\
\hline Mean (SD) & $2766.9(1020.0)$ & $2842.1(926.6)$ & 0.15 & $2928.8(933.3)$ & $2770.5(985.9)$ & 0.28 \\
\hline Unknown & 1 & 1 & & 0 & 2 & \\
\hline \multicolumn{7}{|l|}{ Ratio Placental Weight to Birth Weight } \\
\hline Mean (SD) & $18.0(4.0)$ & $18.3(5.1)$ & 0.67 & $17.9(3.9)$ & $18.3(4.7)$ & 0.67 \\
\hline Unknown & 2 & 2 & & 1 & 3 & \\
\hline \multicolumn{7}{|l|}{ Placental Length (cm) } \\
\hline Mean (SD) & $18.7(3.3)$ & $18.8(3.4)$ & 0.87 & $18.9(3.3)$ & $18.7(3.4)$ & 0.79 \\
\hline Unknown & 0 & 0 & & 0 & 0 & \\
\hline \multicolumn{7}{|l|}{ Placental Width (cm) } \\
\hline Mean (SD) & $15.4(2.7)$ & $16.0(3.4)$ & 0.22 & $15.8(2.9)$ & $15.6(3.1)$ & 0.76 \\
\hline Unknown & 0 & 0 & & 0 & 0 & \\
\hline \multicolumn{7}{|l|}{ Ratio of Placental Length to Width } \\
\hline Mean (SD) & $1.23(0.17)$ & $1.22(0.37)$ & 0.94 & $1.21(0.16)$ & $1.23(0.30)$ & 0.67 \\
\hline Unknown & 0 & 0 & & 0 & 0 & \\
\hline \multicolumn{7}{|l|}{ Placental Weight Centile } \\
\hline Mean (SD) & $66.1(38.1)$ & $67.3(37.6)$ & 0.85 & $74.1(36.9)$ & $64.7(37.9)$ & 0.22 \\
\hline Unknown & 4 & 7 & & 1 & 10 & \\
\hline
\end{tabular}




\begin{tabular}{|c|c|c|c|c|c|c|c|}
\hline \multicolumn{8}{|l|}{ Placental Weight Centile } \\
\hline & $\leq 10^{\text {th }}, \mathrm{n}(\%)$ & $13(16.0)$ & $10(14.5)$ & 0.96 & $4(12.9)$ & $19(16.0)$ & 0.21 \\
\hline & $11-89^{\text {th }}, \mathrm{n}(\%)$ & $27(33.3)$ & $24(34.8)$ & & $7(22.6)$ & $44(37.0)$ & \\
\hline & $\geq 90^{\text {th }}, \mathrm{n}(\%)$ & $41(50.6)$ & $35(50.7)$ & & $20(64.5)$ & $56(47.1)$ & \\
\hline & Unknown & 4 & 7 & & 1 & 10 & \\
\hline
\end{tabular}


Table 9: Logistic regression models for risk of metabolic syndrome. Adjusted for maternal age, pre-pregnancy BMI, gestational age at delivery, severity of PE (mild or severe).

$* \mathrm{p}<0.05$

Metabolic Syndrome Risk

Unadjusted Models
Adjusted Models

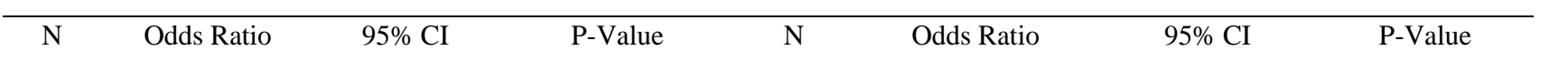

Model 1

Ratio Placental Weight to Birth Weight (\%)

157

0.98

0.90-1.07

0.67

154

0.91

$0.80-1.04$

0.19

Model 2

Ratio Placental Weight to Birth Weight $<15.0 \%$

Ratio Placental Weight to Birth Weight 15-19.9\%

32

\subsection{9}

$0.20-2.38$

0.56

$0.38-2.50$

Ratio Placental Weight to Birth Weight $>20.0 \%$

87

0.98

0.96

Reference

$-$

Model 3

Placental Weight Centile (\%) 150

0.99

$0.98-1.00$

0.22

148

1.00

0.99-1.02

0.50

$0.10-2.53$

0.33-7.36

0.48-6.17

0.57

1.72

Model 4

Placental Weight Centile $\leq 10 \%$
Placental Weight Centile $11-89 \%$
Placental Weight Centile $\geq 90 \%$

23

50

0.17-1.15

0.094
Reference

0.580

$0.25-2.57$
0.77

0.41 
